\title{
The interaction between the measles virus nucleoprotein and the Interferon Regulator Factor 3 relies on a specific cellular environment
}

\author{
Matteo Colombo ${ }^{1,2}$, Jean-Marie Bourhis ${ }^{1,3}$, Celia Chamontin ${ }^{4}$, \\ Carine Soriano ${ }^{4}$, Stéphanie Villet ${ }^{4}$, Stéphanie Costanzo ${ }^{1}$, Marie Couturier ${ }^{1}$, \\ Valérie Belle ${ }^{5}$, André Fournel ${ }^{5}$, Hervé Darbon ${ }^{1}$, Denis Gerlier*4 and \\ Sonia Longhi*1
}

\begin{abstract}
Address: ${ }^{1}$ Architecture et Fonction des Macromolécules Biologiques, UMR 6098 CNRS et Universités Aix-Marseille I et II, 163 Avenue de Luminy, Case 932, 13288 Marseille Cedex 09, France, ²Dept of Biomolecular Sciences and Biotechnology, Universita' degli Studi di Milano, Via Celoria, 26. I-20133 Milan, Italy, ${ }^{3}$ Institut de Biologie et Chimie des Protéines, UMR 5086 CNRS Université de Lyon, 7, passage du Vercors, 69367 Lyon cedex 7, France, ${ }^{4}$ VirPatH, FRE 3011, CNRS and Université Lyon 1, Faculté de Médecine RTH Laennec, 69372, Lyon, France and ${ }^{5}$ Bioénergétique et Ingénierie des Protéines, UPR 9036 CNRS, 31 Chemin Joseph Aiguier, 13402 Marseille Cedex, France, and Université Aix-Marseille I, 3 place Victor Hugo 13331, Marseille, Cedex 3, France

Email: Matteo Colombo - Matteo.Colombo@unimi.it; Jean-Marie Bourhis - Jean-Marie.Bourhis@ibcp.fr;

Celia Chamontin - chamontin_celia@yahoo.fr; Carine Soriano - Carine.Soriano@univ-lyon1.fr; Stéphanie Villet - stephanie.villet@neuf.fr;

Stéphanie Costanzo - Stephanie.Costanzo@afmb.univ-mrs.fr; Marie Couturier - Marie.Couturier@afmb.univ-mrs.fr;

Valérie Belle - Belle@ibsm.cnrs-mrs.fr; André Fournel - Fournel@ibsm.cnrs-mrs.fr; Hervé Darbon - Herve.Darbon@afmb.univ-mrs.fr;

Denis Gerlier* - Denis.Gerlier@univ-lyon1.fr; Sonia Longhi* - Sonia.Longhi@afmb.univ-mrs.fr

* Corresponding authors
\end{abstract}

\section{Published: 15 May 2009}

Virology Journal 2009, 6:59 doi:10.1186/1743-422X-6-59

This article is available from: http://www.virologyj.com/content/6/I/59

(c) 2009 Colombo et al; licensee BioMed Central Ltd.

This is an Open Access article distributed under the terms of the Creative Commons Attribution License (http://creativecommons.org/licenses/by/2.0), which permits unrestricted use, distribution, and reproduction in any medium, provided the original work is properly cited.
Received: II March 2009

Accepted: 15 May 2009

\begin{abstract}
Background: The genome of measles virus consists of a non-segmented single-stranded RNA molecule of negative polarity, which is encapsidated by the viral nucleoprotein $(\mathrm{N})$ within a helical nucleocapsid. The $\mathrm{N}$ protein possesses an intrinsically disordered C-terminal domain (aa $40 \mathrm{I}-525, \mathrm{~N}_{\text {TAIL }}$ ) that is exposed at the surface of the viral nucleopcapsid. Thanks to its flexible nature, $\mathrm{N}_{\text {TAIL }}$ interacts with several viral and cellular partners. Among these latter, the Interferon Regulator Factor 3 (IRF-3) has been reported to interact with $\mathrm{N}$, with the interaction having been mapped to the regulatory domain of IRF-3 and to $\mathrm{N}_{\text {TAIL }}$. This interaction was described to lead to the phosphorylation-dependent activation of IRF-3, and to the ensuing activation of the pro-immune cytokine RANTES gene.

Results: After confirming the reciprocal ability of IRF-3 and N to be co-immunoprecipitated in 293T cells, we thoroughly investigated the $\mathrm{N}_{\text {TAIL }}$-IRF-3 interaction using a recombinant, monomeric form of the regulatory domain of IRF-3. Using a large panel of spectroscopic approaches, including circular dichroism, fluorescence spectroscopy, nuclear magnetic resonance and electron paramagnetic resonance spectroscopy, we failed to detect any direct interaction between IRF-3 and either full-length $\mathrm{N}$ or $\mathrm{N}_{\text {TAIL }}$ under conditions where these latter interact with the $\mathrm{C}$-terminal $\mathrm{X}$ domain of the viral phosphoprotein. Furthermore, such interaction was neither detected in $E$. coli nor in a yeast two hybrid assay.

Conclusion: Altogether, these data support the requirement for a specific cellular environment, such as that provided by $293 \mathrm{~T}$ human cells, for the $\mathrm{N}_{\text {TAIL }}$-IRF-3 interaction to occur. This dependence from a specific cellular context likely reflects the requirement for a human or mammalian cellular co-factor.
\end{abstract}




\section{Background}

Measles virus $(\mathrm{MeV})$ is an enveloped RNA virus within the Morbillivirus genus of the Paramyxoviridae family. Its nonsegmented, negative-sense, single-stranded RNA genome is encapsidated by the viral nucleoprotein $(\mathrm{N})$ within a helical nucleocapsid. Transcription and replication are carried out onto this $\mathrm{N}$ :RNA complex by the viral polymerase complex which consists of two components, the large protein $(\mathrm{L})$ and the phosphoprotein $(\mathrm{P})$ (reviewed in [1]).

$\mathrm{MeV} \mathrm{N}$ consists of two regions: a structured N-terminal moiety, $\mathrm{N}_{\text {CORE }}$ (aa 1-400), which contains all the regions necessary for self-assembly and RNA-binding [2,3], and a C-terminal domain, $\mathrm{N}_{\text {TAIL }}$ (aa 401-525) that is intrinsically unstructured [4] and is exposed at the surface of the viral nucleocapsid $[2,5,6]$.

Intrinsically disordered proteins (IDPs) or protein domains lack highly populated and uniform secondary and tertiary structure under physiological conditions but fulfill essential biological functions [7-19]. Since $N_{\text {TAIL }}$ is intrinsically flexible and is exposed at the surface of the viral nucleocapsid, it interacts with various partners, including the viral $\mathrm{P}$ protein $[3,4]$ and host cell proteins such as the major inducible heat shock protein (Hsp72) $[20,21]$, and the yet uncharacterized Nucleoprotein Receptor (NR) [22,23]. In addition, it has also been reported to interact with the Interferon Regulator Factor 3 (IRF-3) [24].

IRF-3 is ubiquitously expressed as a stable latent transactivator of the cellular innate immune response [25]. It belongs to the family of interferon regulatory factors (IRF) and acts as a transactivator for the interferon- $\beta$ (IFN- $\beta$ ) and various pro-inflammatory cytokine genes. All mammalian IRFs share a conserved N-terminal DNA binding domain (DBD) and a C-terminal interferon association domain (IAD). IRF-3 consists of a DBD (aa 1-110), of a proline-rich region (PRR, aa 112-174), followed by the IAD (aa 175-384) and by a serine-rich region (SRR, aa 385-427) (Figure 1A).

The seminal and unique observation that $\mathrm{MeV} N$ activates IRF-3 to induce CCL5 (also called RANTES), a pro-inflammatory cytokine, but not IFN- $\beta$, was done by the Hiscott's group ?[24]. After $\mathrm{MeV}$ infection, IRF-3 was phosphorylated at the key $\operatorname{Ser}^{385}$ and $\operatorname{Ser}^{386}$ residues, and this form was able to bind to the interferon sensitive response element of ISG15 in complex with CREB binding protein in vitro. Activation of IRF-3, which required active MeV transcription, was also mimicked by the transient expression of the $\mathrm{N}$ protein [24]. Moreover, IRF-3 and a cellular kinase could be co-immunoprecipitated with $N$ [24]. From these data it was assumed that $\mathrm{MeV} \mathrm{N}$ physically interacts with IRF-3 and induces the phosphorylation of the latter by recruiting the kinase. Phosphorylation of IRF3 would then lead to IRF-3 homo-dimerisation, followed by IRF-3 nuclear import and transactivation of a selective set of pro-inflammatory cytokines [24]. Using deletion constructs and co-immunoprecipitation studies, the IRF-3 binding region was grossly mapped to $\mathrm{N}_{\text {TAIL }}$ (residues 415-523), while the $\mathrm{N}$ binding region within IRF-3 was mapped to residues 198-394 [24].

We have previously reported that $\mathrm{N}_{\text {TAIL }}$ undergoes $\alpha$-helical induced folding upon binding to $\mathrm{P}[4]$, and solved the crystal structure of the $P$ domain (XD, aa 459-507) responsible for the $\mathrm{N}_{\text {TAIL }}$ induced folding [26]. Within a conserved region of $\mathrm{N}_{\text {TAIL }}$ (aa 489-506, Box2), we have identified an $\alpha$-helical molecular recognition element ( $\alpha$ MoRE, aa 489-499) [27], involved in the binding to XD and in induced folding $[26,28-30]$. XD-induced $\alpha$-helical folding of the $\mathrm{N}_{\text {TAIL }}$ region encompassing residues 486503 was confirmed by Kingston and co-workers, who solved the crystal structure of a chimeric construct consisting of XD and the 486-504 region of $\mathrm{N}_{\mathrm{TAIL}}$ [31]. Analysis of this structure revealed that the $\alpha$-helix of $N_{\text {TAIL }}$ is embedded in the hydrophobic cleft of XD delimited by helices $\alpha 2$ and $\alpha 3$, to form a pseudo-four helix arrangement that is very frequently found in nature [31].

Analysis of the crystal structure of the regulatory domain (RD, aa 175-427) of IRF-3 (IRF-3 RD, pdb code 1QWT, [32]) (Figure 1B) points out the presence of a triple $\alpha$-helical bundle well superimposable to the structure of $\mathrm{XD}$ (Figure 1C). Furthermore, the triple $\alpha$-helical bundle of IRF-3 also accommodates the nuclear co-activator binding domain (or IbiD domain) of CREB (pdb code 1ZOQ, [33], data not shown), which forms a disordered molten globule in the absence of a binding partner [34] and that folds into an $\alpha$-helical structure upon binding to IRF-3 [33]. We therefore hypothesized that the $\alpha$-helical bundle of IRF-3 may support the ability of IRF-3 to interact with the disordered $\mathrm{N}_{\text {TAIL }}$ domain in a way reminiscent of that of XD.

After confirming the reciprocal ability of IRF-3 and $\mathrm{N}$ to be co-immunoprecipitated in human cells, we undertook the cloning and the bacterial expression of IRF-3 RD in view of obtaining conspicuous protein amounts suitable for further biochemical and biophysical studies aimed at investigating the molecular mechanisms of the $\mathrm{N}_{\text {TAIL }}$-IRF3 interaction. A monomeric form of IRF-3 RD was then purified from the soluble fraction of E. coli, and further used in experiments aimed at ascertaining whether $\mathrm{N}_{\text {TAIL }}$ underwent induced folding upon binding to IRF-3. Using a panel of spectroscopic approaches, including circular dichroism (CD), fluorescence spectroscopy, nuclear magnetic resonance (NMR) and electron paramagnetic reso- 

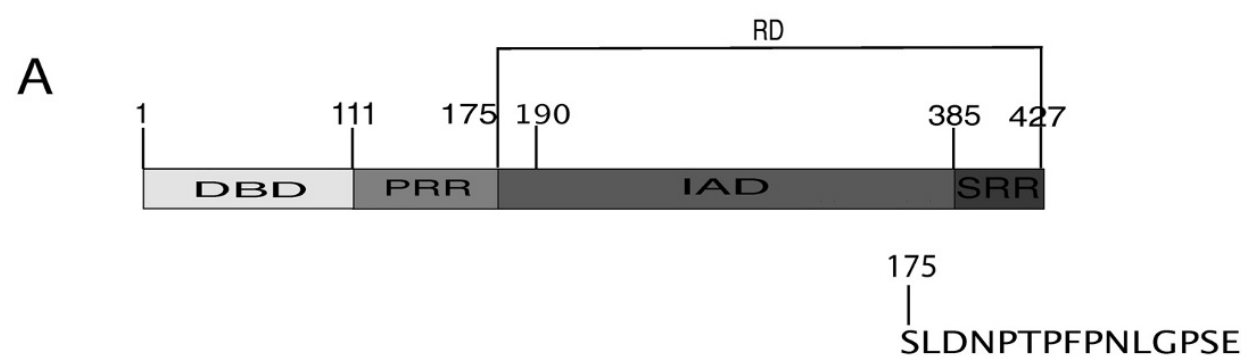

190

NPLKRLLVPGEEWEFEVTAFYRGRQVFQQTISCPEGLRLVGSEVGDRTL

\section{acare}

PGWPVTLPDPGMSLTDRGVMSYVRHVLSCLGGGLALWRAGQWLWAQRL
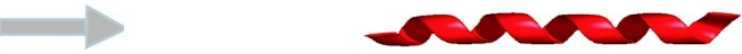

GHCHTYWAVSEELLPNSGHGPDGEVPKDKEGGVFDLGPFIVDLITFTEG
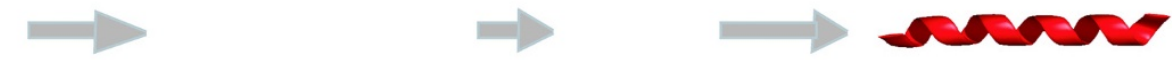

SGRSPRYALWFCVGESWPQDQPW TKRLVMVKVVPTCLRALVEMARVG
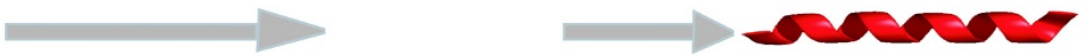

GASSLENTVDLHISNSHPLSLTSDQYKAYLQDLVEGMDFQGPGES
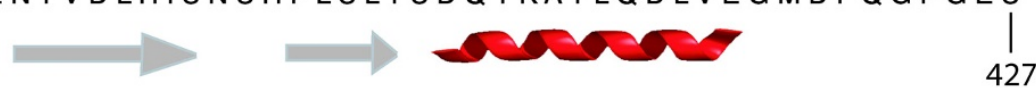

B
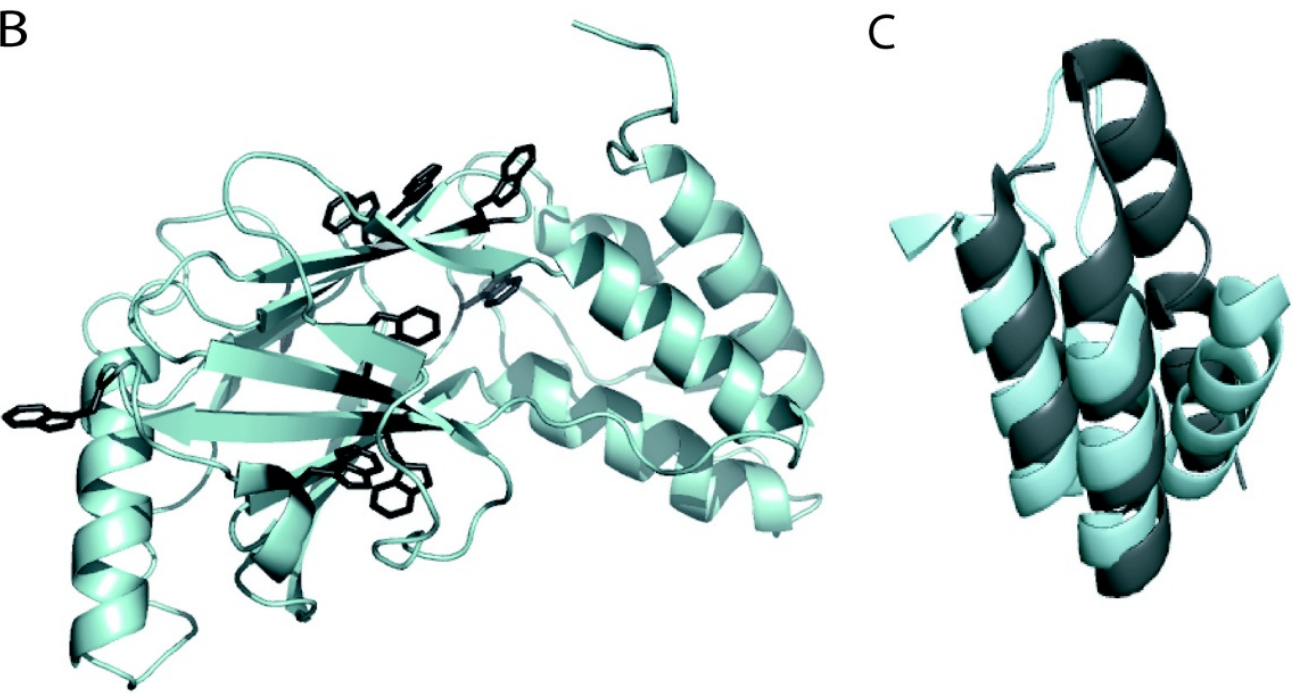

Figure I

(A) Schematic representation of the modular organization of IRF-3. (B) Ribbon representation of the crystal structure of IRF-3 RD (pdb code IQWT) in which the side chains of trp residues are shown in sticks and in dark grey. (C) Superimposition between the crystal structure of IRF-3 RD (light grey) and XD (dark grey, pdb code IOKS). 
nance (EPR) spectroscopy, we failed to document a direct binding of $\mathrm{N}_{\text {TAIL }}$ with IRF-3 RD, under conditions where the $\mathrm{N}_{\text {TAIL }}$-XD interaction was detected. Moreover, the lack of direct interaction of IRF-3 with the full-length $\mathrm{N}$ protein ruled out a possible contribution of the folded $\mathrm{N}_{\text {CORE }}$ domain of $\mathrm{N}$ (aa 1-400) in the interaction with IRF-3. Strikingly, the interaction could not be detected in the bacterial lysate either, nor was it observed using a yeast two hybrid assay. Altogether these results support the requirement of a specific cellular environment for the $\mathrm{N}_{\text {TAIL }}$-IRF-3 interaction to occur.

\section{Methods}

\section{Bacterial strains, primers, restriction enzymes and antibodies}

The E. coli strains DH5 $\alpha$ (Stratagene) or Rosetta [DE3] pLysS (Novagen) were used for selection and amplification of DNA constructs, or for the expression of recombinant proteins, respectively.

Primers were from Invitrogen and Operon. Restriction enzymes, anti-flag mAb, and goat anti-mouse HRP conjugated secondary antibodies were purchased from New England Biolabs, Sigma, and Upstate Laboratories, respectively.

\section{Co-immunoprecipitation of proteins expressed in human cells}

The pCDNA-myc-IRF3 and pEF-BOS-flag-N eukaryotic vectors were derived by PCR and subcloning into a homemade pCDNA-myc and pEF-BOS-flagx2 vector so as to encode N-terminal myc- and flag-tagged IRF-3 and N protein, respectively. 293 T cells $\left(2 \times 10^{6}\right)$ were cotransfected with $12 \mu \mathrm{g}$ of plasmid DNA using Dreamfect-Gold reagent according to OZ BIOSCIENCES' instructions http:// www.ozbiosciences.com/dreamfect.html. Two days after, cells were collected and lysed in $0.3 \mathrm{ml}$ of lysis buffer (50 $\mathrm{mM}$ Tris pH 8.0, 5 mM EDTA, $150 \mathrm{mM} \mathrm{NaCl}$, 0.5\% Igepal CA-630 (Sigma), 1 mM phenyl-methyl-sulphonyl-fluoride (PMSF) and $1 \times$ Complete $^{\circledast}$ (Roche) by 3 passages into a 26G needle for $30 \mathrm{~min}$ on ice. Cell debris were eliminated by centrifugation at 15,000 rpm for $15 \mathrm{~min}$. Then, proteins were immunoprecipitated using rabbit anti-IRF3 (Santa-Cruz) and protein-G-Sepharose ${ }^{\circledR}$ (GE Healthcare Life Sciences) beads and eluted as detailed elsewhere [35]. Alternatively, they were immunoprecipitated using Monoclonal ANTI-FLAG ${ }^{\circledR}$ M2 Affinity Gel and eluted using 3X FLAG ${ }^{\circledR}$ Peptide according to Sigma's instructions. Proteins were then detected by western blotting using the appropriate antibody and peroxydase-conjugate combinations as detailed elsewhere [35].

\section{Cloning of human IRF-3 cDNA}

The cDNA of human IRF3 was obtained by RT-PCR from total RNA extracted from HeLa cells. The RNA extraction method and the RT-PCR were performed as described elsewhere [36]. The IFR-3 cDNA was PCR amplified using forward 5'-CATGAATTCATGGGAACCCCAAAGCCA-3' and backward 5'-TGACTCGAGTCAGCTCTCCCCAGGGCC-3' primers containing EcoRI and XhoI restriction sites (bold), respectively. The cDNA was subcloned downstream the myc tag into an in-house made pcDNA3-myc plasmid. The myc-IRF-3 construct was checked by sequencing.

\section{Construction of IRF-3 RD expression plasmids}

The IRF-3 $\mathrm{RD}_{\mathrm{HN}}$, IRF-3 $\mathrm{RD}_{\mathrm{FN}}$ and IRF-3 $\mathrm{RD}_{\mathrm{HC}}$ gene constructs, encoding residues $175-427$ of the IRF-3 protein with either an hexahistidine tag fused to the N-terminus (IRF-3 RD $\mathrm{HN}_{\mathrm{H}}$ ) or to the C-terminus (IRF-3 RD $\mathrm{HC}_{\mathrm{HC}}$ ), or with a flag sequence (DYKDDDDK) [37] fused to the N-terminus (IRF-3 $\mathrm{RD}_{\mathrm{FN}}$ ), were obtained by recursive PCR, using pIRF-3 as template and Pfx polymerase (Invitrogen). Primers were designed to introduce either a hexahistidine tag encoding sequence (either at the $\mathrm{N}$ - or at the C-terminus of IRF-3 RD) or a flag encoding sequence at the N-terminus of IRF-3 RD, as well as an AttB1 and an AttB2 site allowing further cloning into the pDest 14 vector (Invitrogen) using the Gateway recombination system (Invitrogen). The sequence of the coding region of all the pDest14/IRF-3 RD constructs was checked by sequencing (GenomeExpress).

\section{$X D, N$ and $N_{\text {TAIL }}$ expression plasmids}

The following constructs have already been described: (i) the pDest $14 / \mathrm{XD}_{\mathrm{HC}}$ gene construct, encoding residues 459-507 of the MeV P protein (strain Edmonston B) with a hexahistidine tag fused to its C-terminus, [26], (ii) the N gene construct, pet $21 \mathrm{a} / \mathrm{N}_{\mathrm{FNHC}}$, encoding the $\mathrm{MeV} \mathrm{N}$ protein (strain Edmonston B) with a flag fused at its N-terminus and an hexahistidine tag fused to its C-terminus, [2], (iii) the pDest14/ $\mathrm{N}_{\text {TAILHN }}$ encoding residues $401-525$ of the $w t \mathrm{MeV} N$ protein (strain Edmonston B) with an N-terminal hexahistidine tag [38], and (iv) the $\mathrm{N}_{\text {TAIL }}$ S407C, $\mathrm{N}_{\text {TAIL }}$ L496C and $\mathrm{N}_{\text {TAIL }}$ V517C gene constructs, encoding residues 401-525 of the $\mathrm{MeV} \mathrm{N}$ protein with a Cys substitution at positions 407, 496 and 517 of $\mathrm{N}$, respectively, and with a N-terminal hexahistidine tag [29].

The pDest14/ $\mathrm{N}_{\text {TAILFN }}$ construct, encoding residues 401525 of the $w t \mathrm{MeV} N$ protein (strain Edmonston B) with an N-terminal flag sequence $\left(\mathrm{N}_{\text {TAILFN }}\right)$, was obtained by recursive PCR followed by cloning into the pDest 14 vector. PCR was carried out using pDest $14 / \mathrm{N}_{\text {TAILHN }}$ [38] as template, and Pfu polymerase (Promega). Beyond AttB1 and $A t t B 2$ sites, primers were designed to introduce a flag encoding sequence at the $\mathrm{N}$-terminus of $\mathrm{N}_{\text {TAIL }}$. The coding regions of the $\mathrm{N}_{\text {TAILFN }}$ construct was checked by sequencing (GenomeExpress). 


\section{Expression of recombinant proteins}

The E. coli strain Rosetta [DE3] (Novagen) was used for the expression of the pDest14/IRF-3 RD constructs. Cultures were grown overnight to saturation in Luria-Bertani medium containing $100 \mu \mathrm{g} / \mathrm{ml}$ ampicilin and $17 \mu \mathrm{g} / \mathrm{ml}$ chloramphenicol. An aliquot of the overnight culture was diluted $1 / 12.5$ in $\mathrm{LB}$ medium and grown at $37^{\circ} \mathrm{C}$. At $\mathrm{OD}_{600}$ of 0.7 , the culture was incubated in ice for 2 hours. Then isopropyl $\beta$-D-thiogalactopyranoside (IPTG) and ethanol were added to a final concentration of $50 \mu \mathrm{M}$ and $2 \%(\mathrm{v} / \mathrm{v})$, respectively. Cells were grown at $17^{\circ} \mathrm{C}$ for 16 hours. The induced cells were harvested, washed and collected by centrifugation. The resulting pellets were frozen at $-20^{\circ} \mathrm{C}$.

Isotopically substituted ( $\left.{ }^{15} \mathrm{~N}\right) \mathrm{N}_{\text {TAIL }}$ and ( $\left.{ }^{15} \mathrm{~N}\right)$ IRF-3 RD were prepared by growing bacteria transformed by the pDest $14 / \mathrm{N}_{\text {TAILHN }}$ and pDest14/IRF-3RD $\mathrm{HN}_{\mathrm{H}}$ constructs, respectively, in minimal $\mathrm{M} 9$ medium supplemented with ${ }^{15} \mathrm{NH}_{4} \mathrm{Cl}(0.8 \mathrm{~g} / \mathrm{l})$ [38]. Expression of tagged XD $\left(\mathrm{XD}_{\mathrm{HC}}\right)$ [26], tagged $\mathrm{N}[2], w t$ and cys-substituted $\mathrm{N}_{\text {TAIL }}[4,29,38]$ proteins was carried out as already described.

\section{Purification of recombinant proteins}

Cellular pellets from bacteria transformed with the pDest14/IRF3-RD $\mathrm{HN}_{\mathrm{H}}$ expression plasmid were resuspended in 5 volumes $(\mathrm{v} / \mathrm{w})$ buffer A $(50 \mathrm{mM}$ sodium phosphate $\mathrm{pH} 8,300 \mathrm{mM} \mathrm{NaCl}, 10 \mathrm{mM}$ Imidazole, $1 \mathrm{mM}$ PMSF supplemented with lysozyme $0.1 \mathrm{mg} / \mathrm{ml}$, DNAse I $10 \mu \mathrm{g} / \mathrm{ml}$, protease inhibitor cocktail (Complete ${ }^{\circledR}$ Roche) (one tablet per $50 \mathrm{ml}$ of lysis buffer). After a $20 \mathrm{~min}$ incubation with gentle agitation, the cells were disrupted by sonication (using a $750 \mathrm{~W}$ sonicator and 4 cycles of $30 \mathrm{~s}$ each at $60 \%$ power output). The lysate was clarified by centrifugation at 30,000 g for $30 \mathrm{~min}$. Starting from one liter of culture, the clarified supernatant was incubated for $1 \mathrm{~h}$ with $4 \mathrm{ml}$ Talon resin (Clontech), previously equilibrated in buffer A. The resin was washed with buffer A, and the IRF-3 RD protein was eluted in buffer A containing $250 \mathrm{mM}$ imidazole. Eluates were analyzed by SDSPAGE for the presence of the desired product. The fractions containing the recombinant product were combined, dialyzed against buffer B (20 mM Tris/HCl pH 7.4, $10 \mathrm{mM} \mathrm{NaCl}, 0.1 \mathrm{mM}$ EDTA, $1 \mathrm{mM}$ DTT) and then loaded onto a Hi-Trap Q Fast-Flow $5 \times 1$ column (GE Healthcare). The protein was eluted with a $\mathrm{NaCl}$ gradient (from 25 to $250 \mathrm{mM}$ ). The fractions containing the protein were combined and concentrated using $10 \mathrm{kDa}$ molecular cutoff Centricon Plus-20 (Millipore) prior to loading onto a Superdex 200 HR 10/30 column (GE Healthcare) followed by elution in various buffers. After elution with buffer C (20 mM Hepes pH 7.3, NaCl 100 mM, EDTA 0.1 $\mathrm{mM})$, the fractions corresponding to IRF3 were collected and dialyzed against buffer D (20 mM Hepes pH 7.3,
$\mathrm{NaCl} 10 \mathrm{mM}$, EDTA $0.1 \mathrm{mM})$. The purified protein, referred to as IRF-3 RD, was stored at $-20^{\circ} \mathrm{C}$.

Purification of histidine-tagged N, XD and of $w t$ or cyssubstituted $\mathrm{N}_{\text {TAIL }}$ proteins was carried out as described in $[2,26,29,30,38]$.

All purification steps, except for gel filtrations, were carried out at $4^{\circ} \mathrm{C}$. Protein concentrations were calculated using $\mathrm{OD}_{280}$ measurements and the theoretical absorption coefficients $\varepsilon(\mathrm{mg} / \mathrm{ml} . \mathrm{cm})$ at $280 \mathrm{~nm}$ as obtained using the program ProtParam at the EXPASY server http:/ Lwww.expasy.ch/tools. Apparent molecular mass of proteins eluted from gel filtration columns was deduced from a calibration carried out with Low Molecular Weight (LMW) and High Molecular Weight (HMW) calibration kits (GE Healthcare). The theoretical Stokes radius $\left(\mathrm{R}_{\mathrm{s}}\right)$ of a native $\left(\mathrm{R}_{\mathrm{s}} \mathrm{N}\right)$ protein was calculated according to [39]: $\log \left(\mathrm{R}_{\mathrm{s}} \mathrm{N}\right)=0.369 * \log (\mathrm{MM})-0.254$, with $(\mathrm{MM})$ being the molecular mass (in Daltons) and $\mathrm{R}_{\mathrm{S}}$ being expressed in $\AA$.

\section{Analytical size-exclusion chromatography (SEC) with on- line multi-angle laser light-scattering, absorbance, and refractive index (MALSIUVIRI) detectors}

SEC was carried out on a HPLC system (Alliance 2695, Waters) using a Superose 12 column $(5 \mathrm{ml}$ ) (Amersham, Pharmacia Biotech) eluted with various buffers at a flow of $0.5 \mathrm{ml} / \mathrm{min}$. Detection was performed using a tripleangle light-scattering detector (MiniDAWN ${ }^{\mathrm{TM}}$ TREOS, Wyatt Technology), a quasi-elastic light-scattering instrument (Dynapro ${ }^{\mathrm{TM}}$, Wyatt Technology) and a differential refractometer (Optilab ${ }^{\circledR}$ rEX, Wyatt Technology). Molecular mass and hydrodynamic radius (Stokes radius, $\mathrm{R}_{\mathrm{S}}$ ) determination was performed by the ASTRA V software (Wyatt Technology) using a $d n / d c$ value of $0.185 \mathrm{ml} / \mathrm{g}$. IRF-3 RD was loaded at a final concentration ranging from $0.2 \mathrm{mM}$ to $1.2 \mathrm{mM}$.

\section{Dynamic Light Scattering (DLS)}

Dynamic light scattering experiments were performed with a Nano-S Zetasizer (MALVERN) at $20^{\circ} \mathrm{C}$. All samples were filtered prior to the measurements (Millex syringe filters $0.22 \mu \mathrm{m}$, Millipore). The hydrodynamic radius was deduced from translational diffusion coefficients using the Stokes-Einstein equation. Diffusion coefficients were inferred from the analysis of the decay of the scattered intensity autocorrelation function. All calculations were performed using the software provided by the manufacturer.

\section{Mass Spectrometry (MALDI-TOF)}

Mass analysis of tryptic fragments was carried out using an Autoflex mass spectrometer (Bruker Daltonics). $1 \mu \mathrm{g}$ of purified IRF-3 RD obtained after separation onto $12 \%$ SDS-PAGE was digested with $0.25 \mu \mathrm{g}$ trypsin. The experi- 
mental mass values of the tryptic fragments were compared to theoretical values found in protein data base http://www.matrixscience.com. The mass standards were either autolytic tryptic peptides or peptide standards (Bruker Daltonics).

\section{Spin labeling and EPR spectroscopy}

Spin labeling of cysteine-substituted $\mathrm{N}_{\text {TAIL }}$ variants was carried out as already described $[29,30]$. EPR spectra were recorded at room temperature on an ESP 300E Bruker spectrometer equipped with an ELEXSYS Super High Sensitivity resonator operating at $9.9 \mathrm{GHz}$. Samples were injected in a quartz capillary, whose sensitive volume was about $20 \mu$ l. The microwave power was $10 \mathrm{~mW}$ and the magnetic field modulation frequency and amplitude were $100 \mathrm{kHz}$ and $0.1 \mathrm{mT}$, respectively. Spectra were recorded in buffer $\mathrm{D}$. The concentration of spin-labeled $\mathrm{N}_{\text {TAIL }}$ variants was $20 \mu \mathrm{M}$, while that of IRF-3 RD was $80 \mu \mathrm{M}$.

\section{Circular Dichroism}

Circular dichroism (CD) spectra were recorded on a Jasco 810 dichrograph using $1 \mathrm{~mm}$ thick quartz cells at $20^{\circ} \mathrm{C}$. All spectra were recorded in $10 \mathrm{mM}$ sodium phosphate buffer $\mathrm{pH}$ 7.0.

CD spectra were measured between 185 and $260 \mathrm{~nm}$, at $0.2 \mathrm{~nm} / \mathrm{min}$ and were averaged from three independent acquisitions. The spectra were corrected for water signal and smoothed by using a third-order least square polynomial fit. Protein concentrations of $0.1 \mathrm{mg} / \mathrm{ml}$ were used. Mean ellipticity values per residue $([\Theta])$ were calculated as $[\Theta]=3300 \mathrm{~m} \Delta \mathrm{A} /(\mathrm{l} \mathrm{c} \mathrm{n})$, where l (path length) $=0.1 \mathrm{~cm}$, $\mathrm{n}=$ number of residues, $\mathrm{m}=$ molecular mass in daltons and $\mathrm{c}=$ protein concentration expressed in $\mathrm{mg} / \mathrm{ml}$.

Structural variations of $\mathrm{N}_{\text {TAIL }}$ upon addition of IRF-3 RD were measured as a function of changes in the initial CD spectrum upon addition of two-fold molar excess of IRF$3 \mathrm{RD}$. XD was used as a positive control.

The number of residues (n) is 132 for $\mathrm{N}_{\text {TAILHN }}, 260$ for IRF-3 RD, and 56 for $\mathrm{XD}$, while $\mathrm{m}$ values are $14,632 \mathrm{Da}$ for $\mathrm{N}_{\text {TAILHN }}, 28,903 \mathrm{Da}$ for IRF-3 RD, and 6, $686 \mathrm{Da}$ for XD. In the case of protein mixtures, mean ellipticity values per residue $([\Theta])$ were calculated as $[\Theta]=3300 \Delta \mathrm{A} /\left\{\left[\left(\mathrm{C}_{1} \mathrm{n}_{1}\right) /\right.\right.$ $\left.\left.\left.\mathrm{m}_{1}\right)+\left(\mathrm{C}_{2} \mathrm{n}_{2} / \mathrm{m}_{2}\right)\right] \mathrm{l}\right\}$, where $\mathrm{l}$ (path length) $=0.1 \mathrm{~cm}, \mathrm{n}_{1}$ or $\mathrm{n}_{2}=$ number of residues, $\mathrm{m}_{1}$ or $\mathrm{m}_{2}=$ molecular mass in daltons and $c_{1}$ or $c_{2}=$ protein concentration expressed in $\mathrm{mg} / \mathrm{ml}$ for each of the two proteins in the mixture. The average ellipticity values per residue $\left([\Theta]_{\text {Ave }}\right)$, were calculated as follows: $[\Theta]_{\text {Ave }}=\left[\left([\Theta]_{1} n_{1}\right)+\left([\Theta]_{2} n_{2} \mathrm{R}\right)\right] /\left(\mathrm{n}_{1}+\mathrm{n}_{2}\right.$ $\mathrm{R})$, where $[\Theta]_{1}$ and $[\Theta]_{2}$ correspond to the measured mean ellipticity values per residue, $n_{1}$ and $n_{2}$ to the number of residues for each of the two proteins, and $\mathrm{R}$ to the excess molar ratio of protein 2 . The experimental data in the
$185-260 \mathrm{~nm}$ range were treated using the CDNN software package, which allowed estimation of the $\alpha$-helical content.

\section{Fluorescence spectroscopy}

Fluorescence intensity variations of IRF-3 RD tryptophans were measured by using a Cary Eclipse (Varian) equipped with a front-face fluorescence accessory at $20^{\circ} \mathrm{C}$, by using $2.5 \mathrm{~nm}$ excitation and $10 \mathrm{~nm}$ emission bandwidths. The excitation wavelength was $290 \mathrm{~nm}$ and the emission spectra were recorded between 300 and $450 \mathrm{~nm}$. Titrations were performed in a $1 \mathrm{ml}$ quartz fluorescence cuvette containing $1 \mu \mathrm{M}$ IRF-3 RD in buffer $\mathrm{D}$, and by gradually increasing the concentration of $\mathrm{N}_{\text {TAIL }}$ from $10 \mathrm{nM}$ to $1 \mu \mathrm{M}$. Experimental fluorescence intensities were corrected by subtracting the spectrum obtained with $\mathrm{N}_{\text {TAIL }}$ protein alone (note that $\mathrm{N}_{\text {TAIL }}$ is devoid of tryptophan residues). Data were analyzed by plotting the relative fluorescence intensities at the maximum of emission at increasing $\mathrm{N}_{\text {TAIL }}$ concentrations.

\section{Two-dimensional Heteronuclear Magnetic Resonance}

2D-HSQC spectra [40] were recorded on a 600-MHz ultrashielded-plus Avance-III Bruker spectrometer equipped with a TCI cryo-probe. The temperature was set to $300 \mathrm{~K}$ and the spectra were recorded with 2048 complex points in the directly acquired dimension and 128 points in the indirectly detected dimension, for $6 \mathrm{~h}$ each. Solvent suppression was achieved by the WATERGATE 3-9-19 pulse [41]. The data were processed using the TOPSPIN software, and were multiplied by a sine-squared bell and zerofilled to $1 \mathrm{k}$ in first dimension with linear prediction prior to Fourier transform.

The samples were (i) a $25 \mu \mathrm{M}$ uniformly ${ }^{15} \mathrm{~N}$-labeled $\mathrm{N}_{\text {TAILHN }}$ either alone or after addition of a 4-fold molar excess of IFR-3 RD, and (ii) a $25 \mu \mathrm{M}$ uniformly ${ }^{15} \mathrm{~N}$ labeled IRF-3 RD either alone or after addition of a 2-fold molar excess of full-length $\mathrm{N}$. Spectra were recorded in buffer D containing $10 \% \mathrm{D}_{2} \mathrm{O}(\mathrm{v} / \mathrm{v})$.

\section{Co-immunoprecipitation of proteins expressed in bacteria} Twenty to $80 \mathrm{ml}$ aliquots of induced bacterial cultures expressing either $\mathrm{N}_{\mathrm{TAIL}}$ or IRF-3 RD, were harvested, washed, collected by centrifugation and the resulting pellets were frozen at $-20^{\circ} \mathrm{C}$. Aliquots were individually resuspended in $500 \mu \mathrm{l}$ of buffer $\mathrm{C}$ supplemented with 1 $\mathrm{mM}$ PMSF, $0.1 \mathrm{mg} / \mathrm{ml}$ lysozyme, $10 \mu \mathrm{g} / \mathrm{ml}$ DNAse I, and protease inhibitor cocktail (Complete ${ }^{\circledR}$ Roche). Bacterial lysates were sonicated (using a $750 \mathrm{~W}$ sonicator and 3 cycles of $7 \mathrm{~s}$ at $35 \%$ power output) and were clarified by centrifugation at $16,000 \mathrm{~g}$ for $20 \mathrm{~min}$ at $4{ }^{\circ} \mathrm{C}$. The supernatants, were recovered and filtered onto $0.45 \mu \mathrm{m}$ Ultrafree-MC centrifugal filter devices (Millipore). 
Fifty to $100 \mu \mathrm{l}$ of a bacterial lysate expressing a flagged protein ( $\mathrm{N}_{\text {TAIL }}$ or IRF-3 $\mathrm{RD}$, lysate $\mathrm{A}$ ) were mixed with 60 $\mu \mathrm{g}$ of an anti-flag monoclonal antibody (Sigma-Aldrich), $15 \mu \mathrm{l}$ of Protein A-Sepharose CL 4B (GE Healthcare) (previously equilibrated with 10 volumes of buffer $\mathrm{C}$ ), and buffer $\mathrm{C}$ up to a final volume of $400 \mu \mathrm{l}$ to increase the volume during the binding step. After $1 \mathrm{~h}$ incubation at $4{ }^{\circ} \mathrm{C}$ with gentle agitation, the flow-through was recovered and the resin was washed twice with 20 bed volumes of buffer C. Fifty $\mu \mathrm{l}$ of either a bacterial lysate expressing an unflagged protein ( $\mathrm{N}_{\text {TAIL }}$ lysate $\left.\mathrm{B}\right)$ or of buffer $\mathrm{C}$ containing $5 \mu \mathrm{g}$ of purified unflagged XD (protein B), both corresponding to stoichiometric amounts, were added to the resin and incubation was carried out for one additional hour. The flow-through, containing the unretained fraction, and the resin were recovered and analyzed by SDSPAGE. The $\mathrm{N}_{\text {TAIL }}$-XD couple was used as the positive control. Additional controls included incubation of the immobilized immunoaffinity chromatography (IIAC) resin with either lysates A or lysates/proteins B alone (data not shown). The identity of the co-precipitated or unretained protein bands was confirmed by mass-spectrometry.

\section{Yeast two-hybrid assay}

The following constructs were made by PCR amplification using the pGBKT7- $\mathrm{N}_{\text {TAIL }}$ plasmid [42] as a template: $\mathrm{MeV}$ $\mathrm{N}_{\text {TAIL }}$ (N 401-525), $\mathrm{N}_{\text {TAIL }} \Delta 1$ (N 421-525), $\mathrm{N}_{\text {TAIL }} \Delta 2,3$ (N 401-488), $\mathrm{N}_{\text {TAIL }} \Delta 3$ (N 401-516). They were cloned inframe downstream the GAL4 DNA-binding domain of the pLexAGagB vector (Aptanomics) thus yielding BD-bait fusion proteins named $\mathrm{BD}-\mathrm{N}_{\mathrm{TAlL}}, \mathrm{BD}-\mathrm{N}_{\mathrm{TAIL}} \Delta 1, \mathrm{BD}-$ $\mathrm{N}_{\text {TAIL }} \Delta 2,3$, BD- $\mathrm{N}_{\text {TAIL }} \Delta 3$. PCT (P 231-507) from pGBKT7PCT plasmid [42] and IRF-3 from pcDNA3-myc-IRF-3 were cloned in-frame downstream the GAL4-activating domain of the vector pWP2C (Aptanomics) to yield the $\mathrm{AD}-\mathrm{PCT}$ and AD-IRF3 proteins, respectively. The pLexA (no protein in fusion, $\varnothing$ ), pWP2::RG22C anti-LexA (Ctr+) and pWP2::C5C (Ctr-) plasmids (Aptanomics) were used as controls. All plasmids were checked by sequencing. MB226 $\alpha$ (Leu-Trp-His-Ade-) yeast cells transformed with the BD-bait and pSH1834 (coding for $\beta$-galactosidase as reporter gene) vectors, and MB210a (MAT $\alpha$, Leu-Trp-HisAde-) yeast cells transformed with the AD-prey vectors, were selected on histidine + uracile (SD/-His-Ura), and tryptophan (SD/-Trp) deficient SD medium, respectively. Transformed MB226 $\alpha$ and MB210a cells were mated and grown on Glucose -His-Ura-Trp+X-Gal for successful mating with replicate on Galactose/Raffinose -His-Ura-Trp+XGal for testing the interaction between baits and preys. Experiments were repeated two times. Expression of bait and prey fusion were verified by western blot using antiHA monoclonal antibody as described previously [42].

\section{Results \\ Reciprocal coimmunoprecipitation of myc-IRF-3 and flag- $\mathbf{N}$ proteins}

When co-expressed in human $293 \mathrm{~T}$ cells, flag-N and mycIRF3 formed complexes that could be co-immunoprecipitated by either anti-Flag or anti-IRF-3 antibodies (Figure 2). However, the amount of $\mathrm{N}$ found in the anti-IRF-3 immunoprecipitate was rather limited, since it was detected only after overexposure of the western blot, a condition where the $\mathrm{N}$ signal immunoprecipitated by anti-Flag antibodies is very intense. As controls $\mathrm{N}$ and $\mathrm{P}$ proteins were readily co-immunoprecipitated, while no myc-IRF3/P complex was detected, thus ruling out the possibility that IRF-3 might be aspecifically retained onto the resin (data not shown). Cells expressing myc-IRF3 were used to ascertain antibody specificity in the western blot assay. These results thus confirm those previously obtained by ten Oever et al [24]

\section{Domain analysis of IRF-3 and subcloning of the IRF-3 gene fragment encoding the regulatory domain (RD)}

IRF-3 has a modular organization (see Figure 1A), with the $\mathrm{N}_{\text {TAIL }}$ binding region having been mapped to residues 198-384 [24]. Since the IRF-3 region encompassing residues 175-427 (herein referred to as regulatory domain, $\mathrm{RD})$ was successfully purified from the soluble fraction of

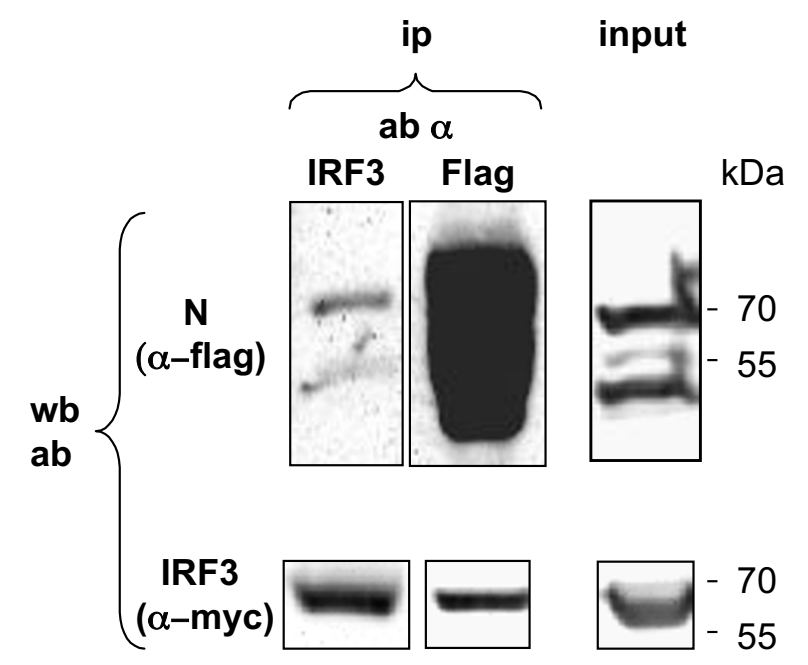

\section{Figure 2}

Reciprocal coimmunoprecipitation of myc-IRF-3 and flag-N proteins. Flag-N was co-expressed with myc-IRF3 in 293T cells and immunoprecipitated by either anti-flag mAb or rabbit polyclonal anti-IRF3 antibodies. After elution by Flagx 3 peptide or Laemli buffer, immunoprecipitated proteins were analysed by Western Blotting using either anti-flag or anti-myc mAb. Note that the western blot was overexposed so as to reveal flag- $\mathrm{N}$ co-immunoprecipitated with myc-IRF-3 
E. coli and further crystallized [32], we cloned the DNA fragment of the IRF-3 gene encoding RD into the pDest 14 expression plasmid. The resulting constructs encode $\mathrm{RD}$ with either an $\mathrm{N}$-terminal or a C-terminal histidine tag.

\section{Expression and purification of a stable, monomeric form of IRF-3 RD}

While the construct encoding IRF-3 RD with a histidinetag at the C-terminus was poorly expressed and mostly insoluble upon induction at $17^{\circ} \mathrm{C}$ (data not shown), the construct bearing the histidine-tag at the $\mathrm{N}$-terminus was well expressed and its solubility was estimated to be approximately 50\% (Figure 3A). IRF-3 RD was purified to homogeneity (> 95\%) in 3 steps: immobilized metal affinity chromatography (IMAC), ion exchange chromatography (IEC) and gel filtration (Figure 3A). The identity of the recombinant product was confirmed by mass spec-
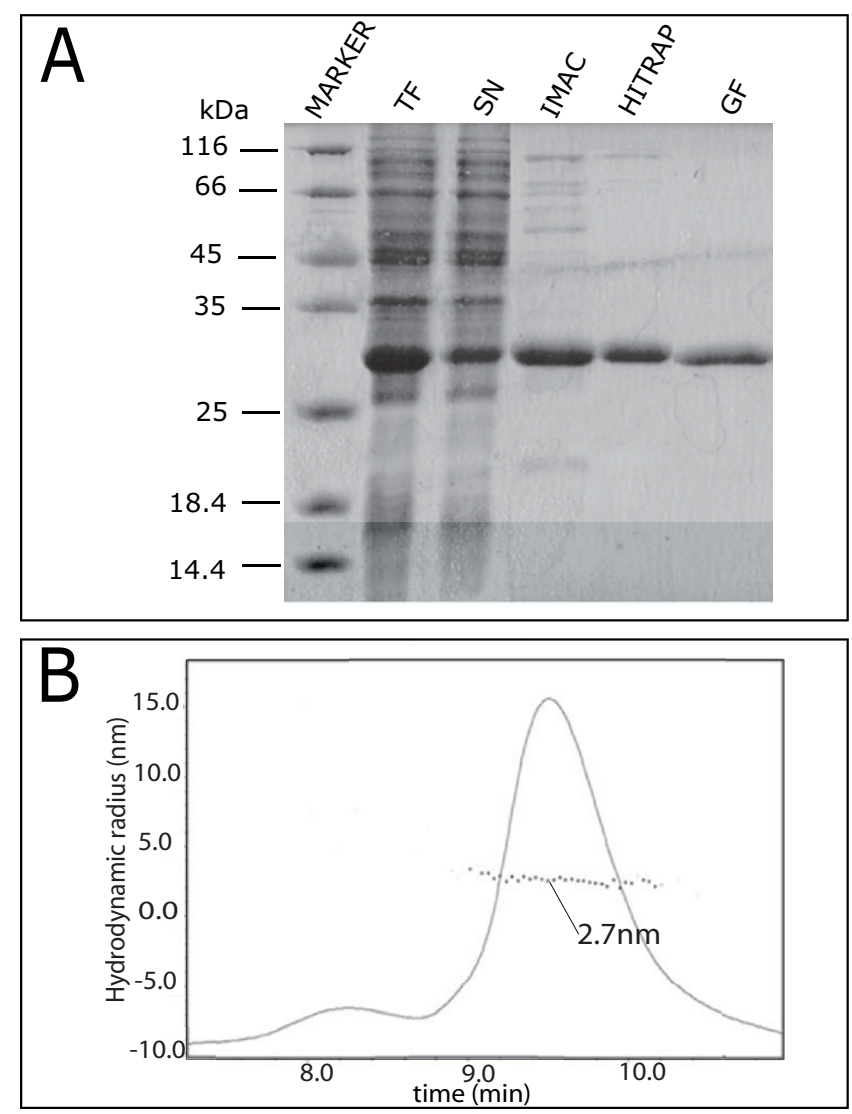

Figure 3

Purification of IRF-3 RD from E. coli. (A) Coomassie blue staining of a I5\% SDS-PAGE. TF: bacterial lysate (total fraction); SN: clarified supernatant (soluble fraction); IMAC: eluent from Immobilized Metal Affinity Chromatography; HITRAP: eluent from lon Exchange Chromatography. GF: eluent from Gel Filtration. (B) Elution profile of IRF-3 RD from analytical SEC-MALS in buffer $C$. The peak containing IRF-3 RD is highlighted and the inferred $R_{S}$ is also shown. trometry analysis of the tryptic fragments obtained after digestion of purified IRF-3 RD.

IRF-3 was reported to undergo dimerization upon phosphorylation induced by MeV N [24,32]. We indeed found that purified, recombinant IRF-3 RD is a dimer under various buffer conditions, including $10 \mathrm{mM}$ sodium phosphate $\mathrm{pH} 7$ or buffer A (data not shown). Since IRF-3 dimerization is the result of a cascade of events triggered by the initial binding of $\mathrm{N}$, we reasoned that the dimeric form of IRF-3 might in principle be expected to exhibit a reduced ability to bind to $\mathrm{N}$. In support of this hypothesis, heteronuclear NMR, EPR and fluorescence experiments carried out with a dimeric form of IRF-3 RD, showed no detectable interaction with $\mathrm{N}_{\text {TAIL }}$ (data not shown).

We therefore screened various combinations of buffers, ionic strengths and salt concentrations in order to identify conditions where IRF-3 RD is a stable monomer. We used SEC-MALS to assess the oligomeric state of purified IRF-3 $\mathrm{RD}$ in various buffers. The experimentally observed $\mathrm{R}_{\mathrm{S}}$ of IRF-3 RD at $0.2 \mathrm{mM}$ in $20 \mathrm{mM}$ Hepes pH 7.3, $\mathrm{NaCl} 100$ $\mathrm{mM}$, EDTA $0.1 \mathrm{mM}$ (buffer C) was $2.7 \mathrm{~nm}$ (Figure 3B), which corresponds to the theoretical value expected for a monomer (approximately $2.5 \mathrm{~nm}$ ) [39]. Moreover, the sharpness and symmetry of the peak indicates the presence of a well-defined molecular species, thus pointing out the homogeneity of the protein sample. Notably, in these buffer conditions, the protein was found to be monomeric in the $0.2-1.2 \mathrm{mM}$ concentration range, thus ruling out a possible effect of sample concentration on oligomerization. DLS analysis showed that the protein remains monomeric in the $0.2-1.2 \mathrm{mM}$ range also after lowering the salt concentration to $10 \mathrm{mM}$ (buffer D). Stability and homogeneity of the sample in buffer D upon prolonged storage at $-20^{\circ} \mathrm{C}$ were checked by DLS. As the oligomeric state of IRF-3 RD was affected by $\mathrm{pH}$ and buffer, all subsequent studies, with the only exception of CD experiments, were carried out in buffer D.

\section{Analysis of the $\mathbf{N}_{\text {TAIL }}$-IRF-3 RD interaction by circular dichroism}

To ascertain that the purified IRF-3 RD protein was properly folded, we recorded its far-UV CD spectrum. Because of significant absorption of buffer $\mathrm{D}$ resulting in highly noisy spectra, the protein $(200 \mu \mathrm{M}$ in buffer D) was diluted to a final concentration of $0.1 \mathrm{mg} / \mathrm{ml}(3.5 \mu \mathrm{M})$ in $10 \mathrm{mM}$ sodium phosphate buffer $\mathrm{pH} 7$. Since the protein was diluted more than 50 times, dimerization under these conditions was assumed to be unlikely. The far-UV CD spectrum of IRF-3 RD (Figure 4A, grey line) is typical of a structured protein with a predominant $\alpha$-helical content, as indicated by the positive ellipticity between 185 and $200 \mathrm{~nm}$, and by the two minima at 208 and $222 \mathrm{~nm}$. The calculated helicity (28.5\%), as obtained using the CDNN 

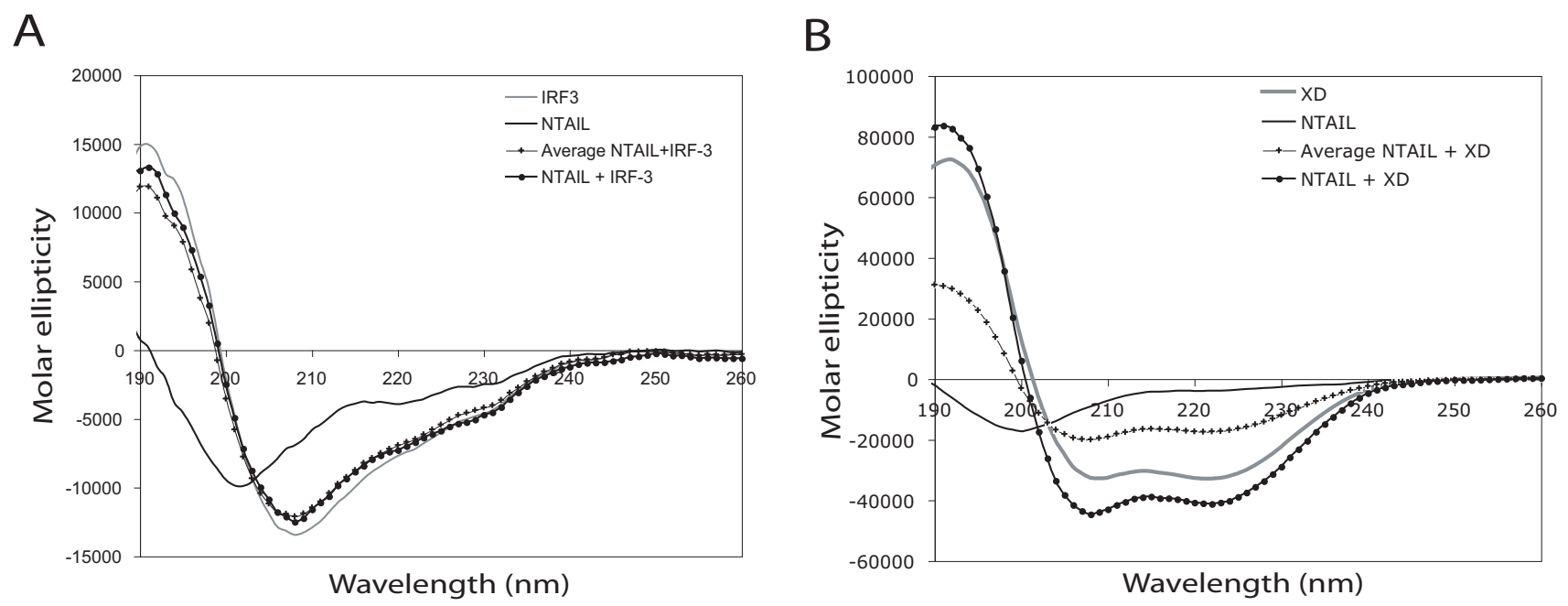

\section{Figure 4}

Analysis of $\mathbf{N}_{\text {TAIL }}$ structural transitions in the presence of IRF-3 RD or XD by far-UV CD. Far-UV CD spectra of $\mathrm{N}_{\text {TAIL }}$ alone (black line) or in the presence of a two-fold molar excess of IRF-3 RD (A) or XD (B). Spectra were recorded in $10 \mathrm{mM}$ sodium phosphate buffer at $\mathrm{pH}$ 7. In the mixture containing $\mathrm{N}_{\text {TAIL }}+$ IRF-3 RD, the concentration of $\mathrm{N}_{\text {TAIL }}$ is I.4 $\mu M$, while that of IRF-3 RD is $2.8 \mu \mathrm{M}$. In the mixture containing $N_{\text {TAIL }}+X D$, the concentration of $N_{\text {TAIL }} 3.5 \mu M$, while that of $X D$ is $7 \mu \mathrm{M}$. The CD spectra of XD or IRF-3 RD alone (grey lines), as well as the theoretical average curves calculated by assuming that no structural variations occur (see Materials and Methods) are also shown. Data are representative of one out of three independent experiments.

software, is in agreement with the $\alpha$-helical content (26.1\%) derived from the analysis of the crystal structure of IRF-3 RD (pdb code 1QWT), thus indicating that the recombinant IRF-3 RD protein is properly folded.

We next addressed the question as to whether IRF-3 RD is able to induce $\alpha$-helical folding of $\mathrm{N}_{\mathrm{TAIL}^{\prime}}$ as already reported for XD [26]. We therefore, recorded the far-UV CD spectrum of $\mathrm{N}_{\text {TAIL }}$ in the presence of a two-fold molar excess of IRF-3 RD (Figure 4A), a condition where XD induces $\alpha$-helical folding of $\mathrm{N}_{\text {TAIL }}$ (Figure $4 \mathrm{~B}$ ). The far-UV $\mathrm{CD}$ spectrum of $\mathrm{XD}$ (Figure $4 \mathrm{~B}$, grey line) is typical of a structured protein with a predominant $\alpha$-helical content. After mixing $\mathrm{N}_{\mathrm{TAIL}}$ with a two-fold molar excess of $\mathrm{XD}$, the observed CD spectrum differs from the corresponding average curve calculated from the two individual spectra (Figure 4B). Since the average curve corresponds to the spectrum that would be expected if no structural variations occur, deviations from this curve indicate structural transitions. The observed deviations are consistent with an XD-induced $\alpha$-helical transition of $\mathrm{N}_{\mathrm{TAIL}}$ as judged by the much more pronounced minima at 208 and $222 \mathrm{~nm}$, and by the higher ellipticity at $190 \mathrm{~nm}$ of the experimentally observed spectrum compared to the corresponding average curve (Figure 4B) [26]. Contrary to XD, the experimentally observed CD spectrum of a mixture containing
$\mathrm{N}_{\text {TAIL }}$ and a two-fold molar excess of IRF-3 RD very well superimposes onto the average spectrum, thus indicating that $\mathrm{N}_{\text {TAIL }}$ undergoes little, if any, structural transitions in the presence of IRF-3 RD (Figure 4A). A further increase in the molar excess of IRF-3 RD resulted in strong dampening of the $\mathrm{N}_{\text {TAIL }}$ signal due to the larger protein size of IRF$3 \mathrm{RD}(28 \mathrm{kDa})$ as compared to $\mathrm{N}_{\mathrm{TAIL}}(14.6 \mathrm{kDa})$ (data not shown). Increasing the $\mathrm{N}_{\text {TAIL }}$ molar excess did not result in any detectable structural transitions either (data not shown).

\section{Analysis of the $\mathbf{N}_{\text {TAIL }}$-IRF-3 RD interaction by heteronuclear NMR spectroscopy}

We next carried out heteronuclear NMR experiments which allowed the use of buffer D, a condition where IRF$3 \mathrm{RD}$ is monomeric, as well as higher concentrations (100 $\mu \mathrm{M})$ of the protein partner. The HSQC spectrum of ${ }^{15} \mathrm{~N}$ uniformly labeled $\mathrm{N}_{\text {TAIL }}$ either alone $(25 \mu \mathrm{M})$ or in the presence of a four-fold molar excess of unlabeled IRF-3 $\mathrm{RD}$ was recorded. The very low spread of the resonance frequencies of $\mathrm{N}_{\text {TAIL }}$ was typical of a disordered protein devoid of stable, highly populated secondary structure (Figure 5A) (see also [4,38]). The HSQC spectrum obtained in the presence of a molar excess of unlabeled IRF-3 RD, pretty well superimposes onto that of $\mathrm{N}_{\text {TAIL }}$ alone, thus pointing out that the ${ }^{15} \mathrm{~N}$ and ${ }^{1} \mathrm{H}_{\mathrm{N}}$ resonance 

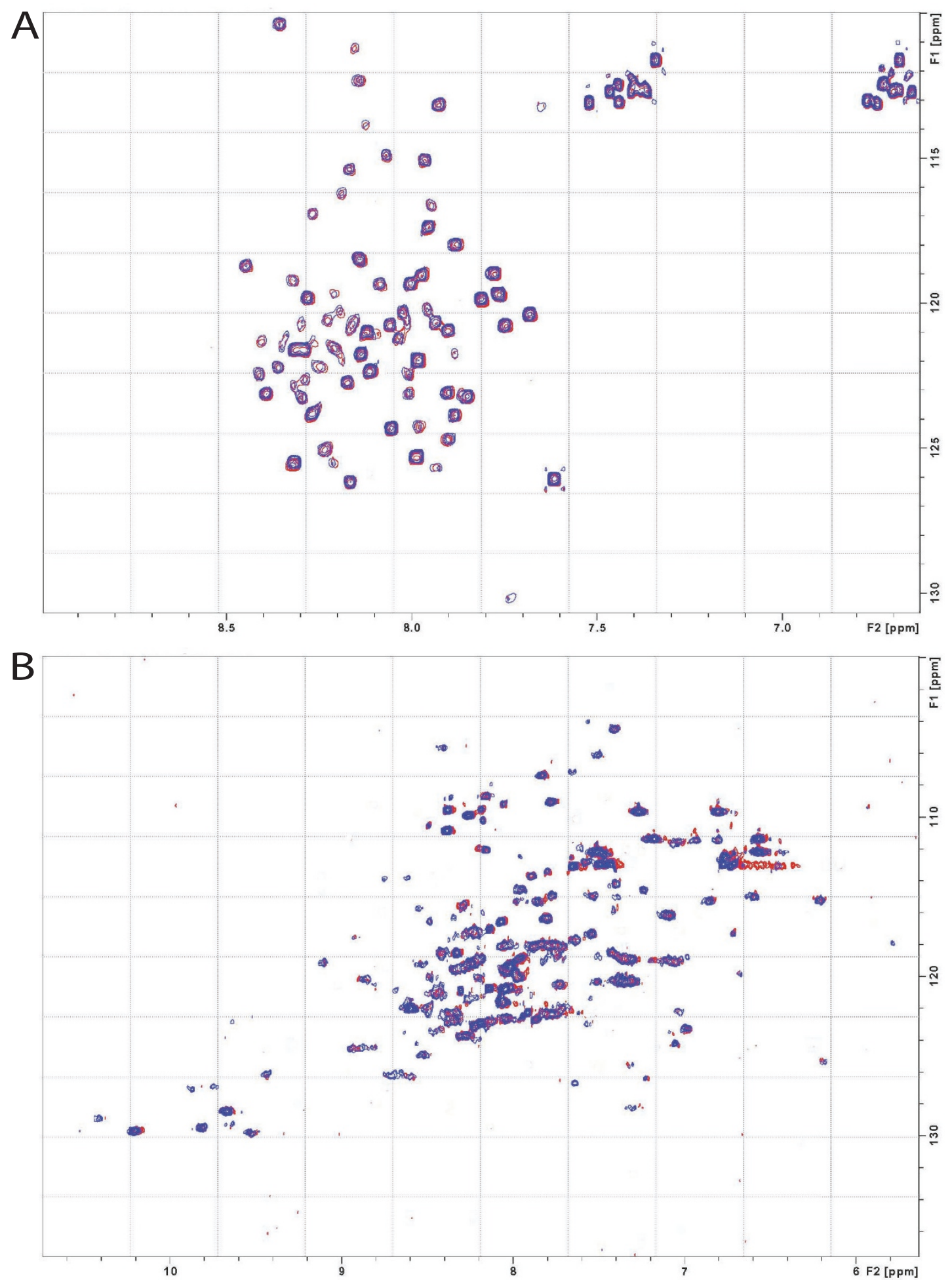

\section{Figure 5}

Analysis of $\mathbf{N}_{\text {TAIL }}$ and IRF3 mutual structural transitions by heteronuclear $\mathbf{N M R}$. $2 \mathrm{D}-\mathrm{HSQC}$ of ${ }^{15} \mathrm{~N}-\mathrm{N}$ TAIL alone (25 $\mu \mathrm{M})$ (in blue) or in the presence of unlabelled IRF-3 (I00 $\mu \mathrm{M})$ (in red) (A) and of I5N-IRF-3 alone (25 $\mu \mathrm{M})$ (in blue) or in the presence of unlabelled $\mathrm{N}(50 \mu \mathrm{M})$ (in red) (B). Spectra were recorded in buffer $\mathrm{D}$. 
frequencies of $\mathrm{N}_{\text {TAIL }}$ were not affected by the addition of IRF-3 RD. These data clearly indicate a lack of interaction between $\mathrm{N}_{\text {TAIL }}$ and IRF-3 RD.

In order to assess whether $\mathrm{N}_{\text {TAIL }}$ was able to interact with IRF-3 RD only in the context of the full-length, autoassembled nucleoprotein, a HSQC spectrum of ${ }^{15} \mathrm{~N}$ uniformly labeled IRF-3 RD, either alone $(25 \mu \mathrm{M})$ or in presence of a 2-fold molar excess of full-length nucleoprotein was also recorded. The HSQC spectrum of ${ }^{15} \mathrm{~N}$ IRF-3 RD was typical of a folded protein, as judged on the basis of the spread of the proton resonances in the 7 to $10 \mathrm{ppm}$ range (Figure 5B). Notably, after addition of unlabeled N, no peak displacement was observed (Figure 5B).

In conclusion, upon mixing IRF-3 RD with either $\mathrm{N}_{\text {TAIL }}$ or the full-length nucleoprotein no magnetic perturbation of the labeled protein was observed.

\section{Analysis of the $\mathrm{N}_{\text {TAIL }}$ IRF-3 RD interaction by site-directed spin-labeling EPR spectroscopy}

The ability of $\mathrm{N}_{\text {TAIL }}$ to interact with IRF-3 RD was next assessed by using site-directed spin-labeling (SDSL) EPR spectroscopy. The basic strategy of this technique involves the introduction of a paramagnetic nitroxide side chain at a selected protein site. This is usually accomplished by cysteine-substitution mutagenesis, followed by covalent modification of the unique sulfydryl group with a selective nitroxide reagent, such as the methanethiosulfonate (MTSL) derivative (for reviews see [43-45]). Then, EPR spectroscopy is used to monitor variations in the mobility of the spin label in the presence of ligands or protein partners.

We thus used three spin-labeled $\mathrm{N}_{\text {TAIL }}$ variants, namely S407C, L496C and V517C, which possess a nitroxide spin label covalently grafted at positions 407, 496 and 517, respectively (Figure 6) [29]. We then recorded the EPR spectra of these spin-labeled $\mathrm{N}_{\text {TAIL }}$ proteins either alone (Figure 6, solid line) or in the presence of either a fourfold molar excess of IRF-3 RD (Figure 6, left panel, dotted line) or of a two-fold molar excess of XD (Figure 6, right panel, dotted line). Experiments were carried out in buffer $\mathrm{D}$, a condition where IRF-3 RD is monomeric. The addition of a two-fold molar excess of XD significantly affects the spectral shape of the spin-labeled L496C and V517C $\mathrm{N}_{\text {TAIL }}$ variants, with strong and moderate effects, respectively (Figure 6, right panel) (see also [29]). Conversely,

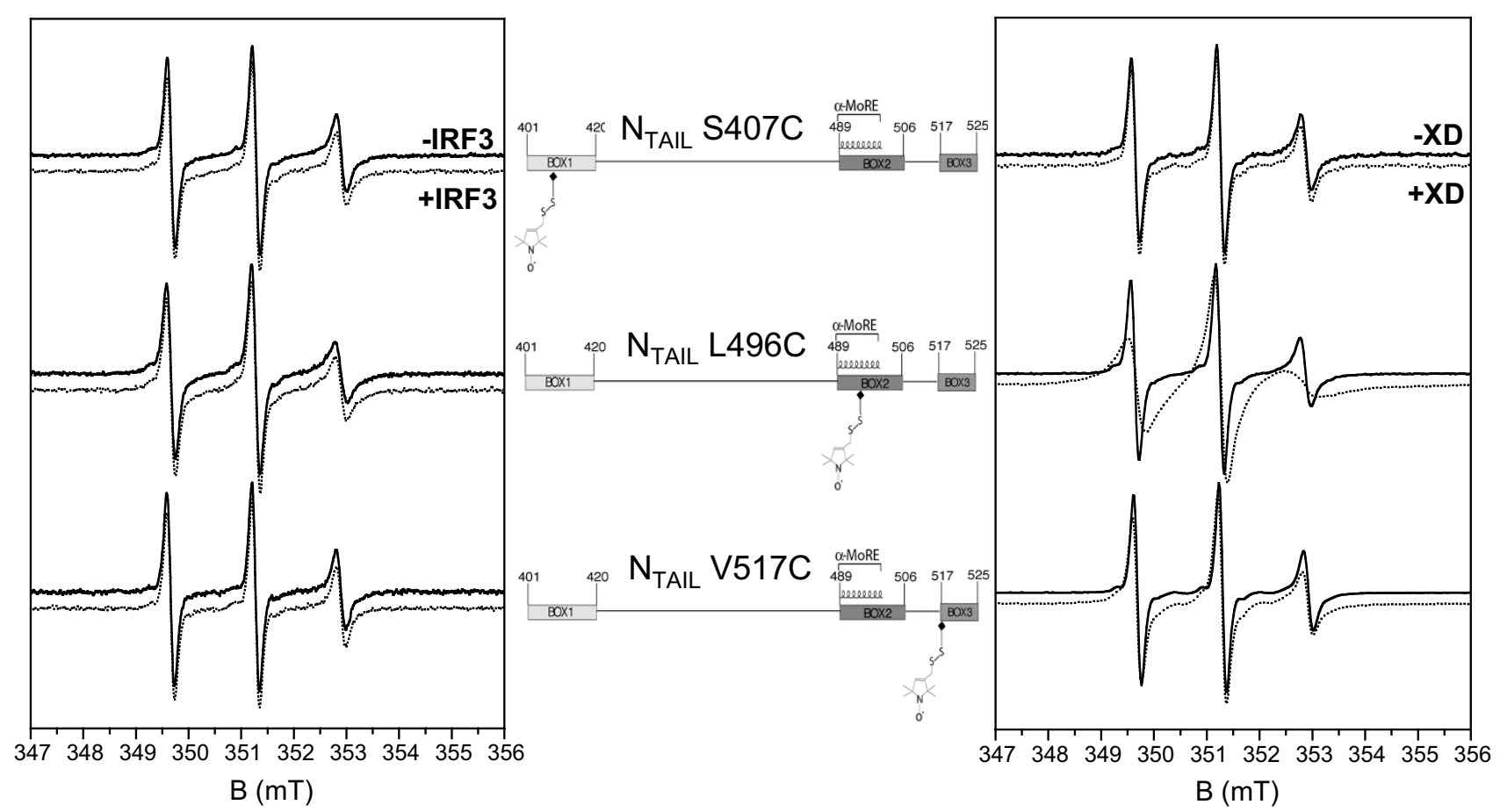

\section{Figure 6}

Analysis of $\mathbf{N}_{\text {TAlL }}$ structural transitions in the presence of IRF-3 RD by EPR spectroscopy. Normalized room temperature EPR spectra of three spin-labeled $\mathrm{N}_{\text {TAlL }}$ proteins $(20 \mu \mathrm{M})$ either in the absence or presence of a four-fold molar excess of IRF-3 RD (left panel) or in the absence or presence of a two-fold molar excess of XD (right panel). Spectra were recorded in buffer $\mathrm{D}$. The schematic representation of each spin-labeled $\mathrm{N}_{\text {TAIL }}$ protein is shown. The spin-label is highlighted. 
no significant impact of XD on the mobility of the spin label grafted at position 407 was observed (Figure 6, right panel) (see also [29]), in agreement with the well-established lack of involvement of this site in binding to $\mathrm{XD}$ [38]. Notably, addition of IRF-3 RD does not trigger any significant variation in the spectral shape in any of the spin-labeled $\mathrm{N}_{\text {TAIL }}$ variants (Figure 6, left panel), thus supporting lack of involvement of the $\mathrm{N}_{\text {TAIL }}$ regions close to the spin-label in the interaction with IRF-3 RD.

\section{Analysis of the $N_{\text {TAIL- IRF-3 RD interaction by intrinsic }}$ fluorescence spectroscopy}

We next studied the possible impact of $\mathrm{N}_{\text {TAIL }}$ on the fluorescence emission of IRF-3 RD. While $\mathrm{N}_{\text {TAIL }}$ is devoid of trp, IRF-3 RD possesses 9 trp residues. IRF-3 RD has a maximum of fluorescence emission at $343 \mathrm{~nm}$ (data not shown). Titration experiments were performed in buffer $\mathrm{D}$, a condition where IRF-3 RD is monomeric. Addition of gradually increasing $\mathrm{N}_{\text {TAIL }}$ concentrations (from $1 \mathrm{nM}$ up to $1 \mu \mathrm{M}$ ) did not trigger any significant variation in the wavelength of emission or in the fluorescence intensity of IRF-3 RD (data not shown), indicating that the chemical environment of the trp residues of IRF-3 RD is not modified in the presence of $\mathrm{N}_{\mathrm{TAIL}}$.

\section{Analysis of the $\mathrm{N}_{\text {TAIL }}$-IRF-3 RD interaction in bacterial lysates}

In order to assess whether the interaction between $\mathrm{N}_{\text {TAIL }}$ and IRF-3 RD required a cellular co-factor possibly occurring in prokaryotic cells, we tested the $\mathrm{N}_{\text {TAIL }}$-IRF-3 RD interaction in bacterial lysates by using co-immunoprecipitation. All experiments were carried out in buffer $\mathrm{C}$, thus ensuring a monomeric state of IRF-3 RD.

After incubating stoichiometric amounts of histidine tagged XD with a resin coated with an anti-flag $\mathrm{mAb}$ and flagged $\mathrm{N}_{\text {TAIL }}$ XD was only found in the retained fraction, consistent with the ability of these proteins to interact (Figure 7). Conversely, upon addition of stoichiometric amounts of a bacterial lysate expressing histidine tagged $\mathrm{N}_{\text {TAIL }}$ to a resin coated with IRF-3 RD, $\mathrm{N}_{\text {TAIL }}$ was found in both unretained and retained fractions (Figure 7). Note that the occurrence of unflagged $\mathrm{N}_{\text {TAIL }}$ in the retained fraction was not due to the ability of IRF-3 RD to co-precipitate the former on the resin, but rather to the lack of a washing step, thus leading to an equal repartition of $\mathrm{N}_{\text {TAIL }}$ in the unretained and retained fractions. These results showed that while the monoclonal anti-flag antibodies co-immunoprecipitated $\mathrm{N}_{\text {TAIL }}$ and purified XD, they failed to co-immunoprecipitate IRF-3 RD and $\mathrm{N}_{\text {TAIL }}$ from bacterial lysates.

Analysis of interaction in yeast using the two-hybrid assay To assess whether the interaction between IRF-3 and MeV $\mathrm{N}_{\text {TAIL }}$ could require an eukaryotic cellular context, we stud-

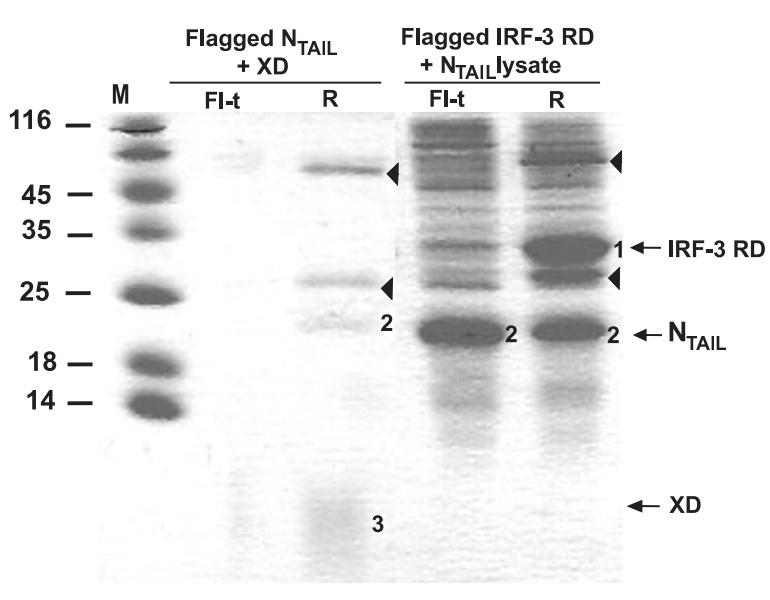

\section{Figure 7}

Co-immunoprecipitation by an anti-flag mAb. Coomassie blue staining of a I8\% SDS-PAGE. Bacterial lysates expressing flagged $\mathrm{N}_{\text {TAlL}}$, flagged IRF-3 RD, or histidine-tagged $N_{\text {TAlL }}$ were used. Purified unflagged $X D$ was also used. Fl-t: flow-through (unretained fraction). R: retained fraction. Arrowheads show the light and heavy chains of the $\mathrm{mAb}$, which are visible on the gel at around 25 and $55 \mathrm{kDa}$, respectively. Numbers I to 3 highlight IRF-3 RD, $N_{\text {TAIL }}$ and $X D$ bands, respectively.

ied this interaction in yeast using the Lex-A two hybrid assay. The successful mating of yeast cells expressing $\mathrm{AD}$ prey and BD-bait constructs was verified by the growth in the glucose-His-Trp + X-Gal supplemented medium (Figure $8 \mathrm{~A}$, left panel). Despite the expression of the protein (Figure 8B), the full length IRF-3 fused to Lex-A-activating domain (AD-IRF-3) did not react with any of the BD-N $\mathrm{N}_{\text {TAIL }}$ constructs (Figure 8A) as shown by lack of growth in galactose/raffinose -His-Ura-Trp + X-Gal medium and lack of the reporter $\beta$-galactosidase enzymatic activity. As controls, an AD-peptide aptamer anti-LexA (Ctr+), but not an irrelevant $\mathrm{AD}$-aptamer (Ctr-), reacted with all Lex-Abaits, while AD-PCT reacted only with BD-N $\mathrm{TAIL}_{\text {, }}$ BD-N $\mathrm{N}_{\Delta 1}$ and $B D-N_{\Delta N 3}$, and not with BD- $\varnothing$ or with $B D-N_{\Delta 2,3}$ as expected.

\section{Discussion}

We herein report the bacterial purification of the regulatory domain of IRF-3 and showed that the buffer conditions strongly affect its oligomerization state. Indeed, the protein was shown to exist in either a dimeric or monomeric state depending on the buffer and the ionic strength. Since MeV N was reported to trigger the phosphorylation-dependent dimerization of IRF-3 [24,32], we reasoned that the dimeric form of this latter might in principle be expected to exhibit a reduced or null ability to interact with $\mathrm{N}_{\text {TAIL }}$. This hypothesis was indeed experimentally confirmed, where various spectroscopic 
(A)

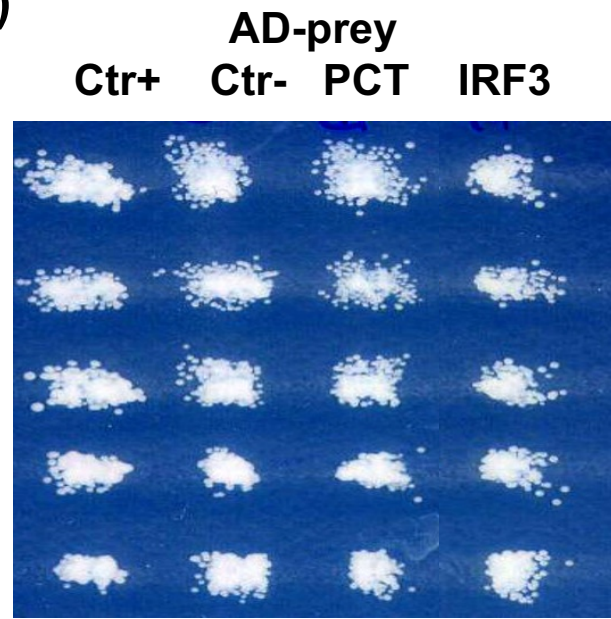

Glucose -His-Ura-Trp + X-Gal
BD-bait
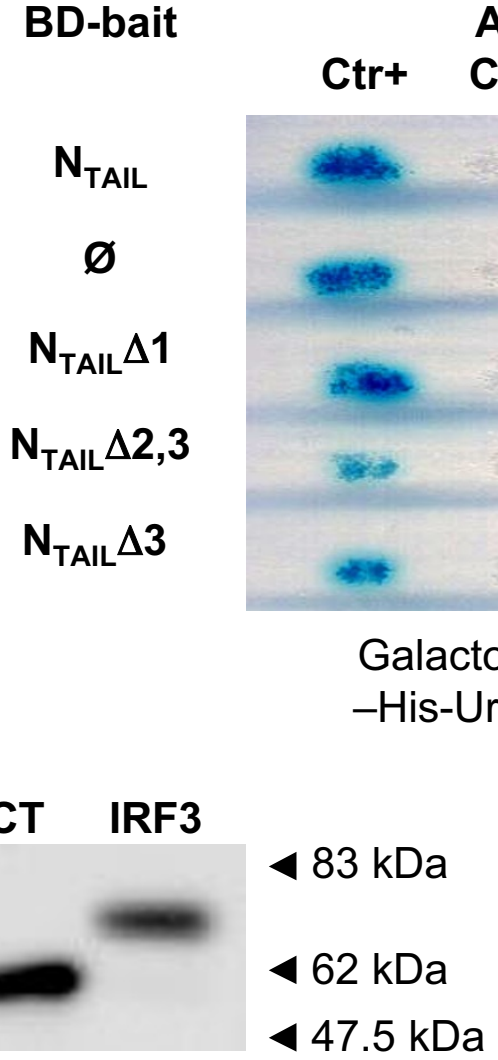

Figure 8

Analysis of IRF-3 and $\mathbf{N}_{\text {TAIL }}$ interaction in yeast. (A) Yeast growth and X-gal expression after co-transformation with bait-LexA and BD-prey encoding plasmid in glucose -His-Trp + X-Gal and in galactose/raffinose -His-Ura-Trp + X-Gal medium. (B) IRF-3-LexA and PCT-LexA expression level in yeast detected by western blot using anti-HA mAb. Ctr+ is the anti-LexA peptide aptamer RG22C, Ctr- is the irrelevant peptide aptamer C5C. $\varnothing$ indicates LexA alone.

approaches failed to detect an interaction between $\mathrm{N}_{\text {TAIL }}$ and the dimeric form of IRF-3 RD (data not shown). We therefore searched for conditions where IRF-3 RD was found to be a stable monomer up to protein concentrations as high as $1 \mathrm{mM}$. We then used the monomeric form of IRF-3 RD for a thorough analysis of its ability to interact with $\mathrm{N}_{\mathrm{TAIL}}$. Using various spectroscopic approaches, we failed to point out any detectable interaction between IRF$3 \mathrm{RD}$ and $\mathrm{N}_{\text {TAIL }}$ under conditions where this latter interacts with the $\mathrm{X}$ domain of the phosphoprotein

Lack of deviations of the experimentally observed CD spectrum of an $\mathrm{N}_{\text {TAII }}$ /IRF-3 RD mixture from the average CD spectrum can be accounted for by assuming that either $\mathrm{N}_{\text {TAIL }}$ does not interact with IRF-3 RD under these experimental conditions, or that their interaction does not imply any significant, concomitant structural rearrangement. It should be pointed out that this spectroscopic approach has been already shown to be sensitive enough to unveil $\alpha$-helical transitions involving as few as $17 \mathrm{~N}_{\text {TAIL }}$ residues out of $125[26,28]$ (see also Figure 3B). That CD was sensitive enough to detect a possible $\mathrm{N}_{\text {TAIL }}$ folding of the same extent as that observed in the presence of XD, was checked and confirmed by the fact that the experimentally observed CD spectrum of a 1:2 mixture of $\mathrm{N}_{\text {TAIL }}$ and IRF-3 RD significantly deviates from a simulated CD spectrum corresponding to a 1:2 mixture of "folded" $\mathrm{N}_{\mathrm{TAIL}}$ and IRF-3 RD. The CD spectrum of "folded" $\mathrm{N}_{\text {TAIL }}$ was calculated from the $\mathrm{CD}$ spectrum of a mixture containing $\mathrm{N}_{\text {TAIL }}$ and XD in the 1:2 molar ratio upon subtraction of the XD contribution (data not shown).

On the other hand, in CD experiments, inability of IRF-3 $\mathrm{RD}$ to interact with $\mathrm{N}_{\text {TAIL }}$ could arise either from possible dimerization of IRF-3 RD in sodium phosphate buffer, with subsequent loss of binding ability, or from the use of protein concentrations below the actual $\mathrm{K}_{\mathrm{D}}$. Indeed, while the $\mathrm{N}_{\mathrm{TAIL}}$ and XD concentrations (3.5 and $7 \mu \mathrm{M}$, respec- 
tively) are well above the reported $\mathrm{K}_{\mathrm{D}}(100 \mathrm{nM})$ [38], the $\mathrm{K}_{\mathrm{D}}$ between $\mathrm{N}_{\text {TAIL }}$ and IRF-3 RD is not known. Hence, the experimentally used $\mathrm{N}_{\text {TAIL }}$ and IRF-3 RD concentrations (1.4 and $2.8 \mu \mathrm{M}$, respectively) might be not high enough to allow a productive interaction.

In order to circumvent these problems, we carried out NMR experiments, which allowed both use of buffer $\mathrm{D}$, a condition where IRF-3 RD was shown to be monomeric, and of protein concentrations as high as $100 \mu \mathrm{M}$. Under these conditions, no interaction was detected between IRF-3 RD and either $\mathrm{N}_{\text {TAIL }}$ or the full-length nucleoprotein. Lack of interaction with $\mathrm{N}$ ruled out the possibility that IRF-3 RD might interact with $\mathrm{N}_{\text {TAIL }}$ only in the context of a self-assembled nucleocapsid-like structure. Noteworthy, using comparable protein concentrations, heteronuclear NMR has already been proven to be sensitive enough to document the XD-induced folding of $\mathrm{N}_{\mathrm{TAIL}}$, where from a total of 125 residues, 11 were shown to undergo an $\alpha$-helical transition and seven a less dramatic conformational change [38]. The $\mathrm{N}_{\text {TAII }}$-XD interaction is however characterized by a high affinity, with an estimated $K_{D}$ of $100 \mathrm{nM}$ [38]. We could speculate that if the $\mathrm{N}_{\text {TAIL }}$-IRF-3 RD binding affinity is much weaker, then this would result in little complex formation, thus escaping detection. However, it should be pointed out that heteronuclear NMR has been already proven to be sensitive enough to document protein-protein interactions characterized by $K_{D}$ values up to the mM range (for a review see [46]). Notably, using protein concentrations similar to those used in this study, heteronuclear NMR successfully unveiled the weak-affinity interaction $\left(K_{D} 10 \mu \mathrm{M}\right)$ between the intrinsically disorder cyclin-dependent inhibitor p21 and Cdk2 [47].

Furthermore, if we assume that in HSQC experiments the percentage of the $\mathrm{N}_{\text {TAII }} /$ IRF-3 RD complex is as low as $10 \%$, which could indeed escape detection, then the corresponding calculated $\mathrm{K}_{\mathrm{D}}$ would be approximately 0.9 $\mathrm{mM}$, based on the following equation

$$
\mathrm{K}_{\mathrm{D}}=\left(\left[\mathrm{A}_{\text {Tot }}-\mathrm{A}_{\text {Bound }}\right]\left[\mathrm{B}_{\mathrm{Tot}}-\mathrm{B}_{\text {Bound }}\right]\right) /[\mathrm{AB}]
$$

A $K_{D}$ in the $\mathrm{mM}$ range would support a fortuitous interaction at best, assuming an IRF-3 intracellular concentration of approximately $1 \mu \mathrm{M}$, as calculated assuming an overall intracellular protein concentration of $200 \mathrm{mg} / \mathrm{ml}$ and that IRF-3 represents approximately $1 / 4000$ of total cellular proteins [48].

Using SDSL EPR spectroscopy and a monomeric form of IRF-3 RD, we failed to point out an impact of this latter on the mobility of three spin labels grafted within $\mathrm{N}_{\text {TAIL }}$. These results support a lack of involvement of the three spin-labeled sites in the interaction and/or a lack of interaction between $\mathrm{N}_{\text {TAIL }}$ and IRF-3 RD. Although this former hypothesis could not be formally ruled out, the spin labels are located within three $\mathrm{N}_{\text {TAIL }}$ regions that can be expected to be involved in the possible interaction with IRF-3 RD, since they are conserved within Morbillivirus members [49] and have been shown to play a functional role in the molecular partnership of $\mathrm{N}_{\text {TAIL }}$ : indeed, Box1 is involved in the interaction with a yet unidentified nucleoprotein cellular receptor $[22,23]$, while Box2 and Box3 participate to binding to both Hsp72 [20,21] and XD $[28,29,38]$. Besides, it is worthy to mention that spin-label EPR spectroscopy has already been proven to be well suited to monitor low-affinity interactions, such as binding of spin-labeled ATP to the multi-drug resistance Pglycoprotein that is characterized by a $K_{D}$ of approximately $700 \mu \mathrm{M}[50]$.

Lack of $\mathrm{N}_{\text {TAIL }}$ impact on the intrinsic trp fluorescence of IRF-3 RD could reflect either a lack of interaction between the proteins, or a location of the IRF-3 RD trp residues outside the region of interaction. This latter hypothesis is however unlikely, since the 9 trp residues are scattered on the whole IRF-3 RD surface (see Figure 1B), with two of them being located in the proximity of the triple $\alpha$-helical bundle that is supposed to correspond to the putative binding site, based on its similarity to the $\mathrm{XD}$ structure (see pdb file 1QWT) and on its involvement in the binding of the (otherwise disordered) IBiD domain of CREB (see pdb file 1ZOQ). Taking into account the fact that fluorescence spectroscopy has been already successfully used to monitor the interaction between XD and a single-site tryptophan-substituted $\mathrm{N}_{\text {TAIL }}$ variant [38] and has also been reported to be able to unveil weak affinity interactions with a $K_{D}$ in the $20-30 \mu \mathrm{M}$ range [51], these data argue for a lack of direct interaction between IRF-3 RD and $\mathrm{N}_{\text {TAIL }}$.

Since co-immunoprecipitation experiments carried out by both tenOever et al. [24] and ourselves, suggest that $\mathrm{N}$ and IRF-3 interact somehow, the hypothesis can be drawn that a specific cellular context is required for the interaction to occur. We therefore questioned whether a bacterial lysate could provide such a context. The interaction was thus tested in crude E. coli lysates using a co-immunoprecipitation protocol in which no washing step was carried out, a method derived from the "hold-up" technique that is well adapted for the detection of low-affinity interactions with $\mathrm{K}_{\mathrm{D}}$ values as high as $50 \mu \mathrm{M}$ [52]. Notably, and in spite of the fact that the experimental design was in principle expected to allow documentation of low-affinity and kinetically transient complexes, no interaction could be detected. Likewise, using the yeast two-hybrid assay, an approach that has been already successfully used to document $\mathrm{MeV}$ protein-protein interactions [42], no interaction was detected in the yeast cellular context either. 


\section{Conclusion}

Altogether, the results herein presented indicate that the $\mathrm{N}_{\text {TAIL }}$-IRF-3 interaction requires a specific eukaryotic cellular environment, such as that provided by $293 \mathrm{~T}$ cells. That a specific cellular context is required for efficient $\mathrm{MeV}$ RNA synthesis has been already reported [53] and argue for the requirement of unknown cellular co-factor(s) in conferring competence for both transcription and replication to viral nucleocapsids. In the case of the $\mathrm{N}_{\text {TAIL }}$-IRF-3 interaction, the strict dependence from a particular cellular context may reflect the requirement of either a humanor mammalian-specific post-translational modification of one or both interactors, or of a human or mammalian cellular co-factor, which would act as a bridge thereby promoting the N-IRF-3 association. In support of this last hypothesis, intrinsically disordered proteins are known to often display weak affinities towards their partners $[7,15]$, thus leading to complexes that are not stable by themselves and must be strengthened by the combination of other interactions or by multimerization (for examples within the replicative complex of $\mathrm{MeV}$ see [54]). In further support of the requirement for a cellular co-factor, tenOever et al. found that the $\mathrm{N}$ protein associated with both IRF-3 and the IRF-3 virus-activated kinase suggesting that both proteins are part of a large complex that favors the colocalization of the kinase and of its substrate [24]. In addition, as $\mathrm{MeV}$ infection (or $\mathrm{MeV} \mathrm{N}$ transfection) triggers binding of IRF-3 to the CREB binding protein to form a complex that activates target genes in the nucleus $[24,55]$, it is also possible that recognition of $\mathrm{N}$ by IRF-3 could be promoted by the CREB binding protein.

Preparative co-immunoprecipitation experiments coupled to mass spectrometry are in progress in view of either ascertaining a role for the virus-activated kinase or the CREB binding protein, or identifying a possible cellular co-factor distinct from these two latter cellular proteins.

\section{Competing interests}

The authors declare that they have no competing interests.

\section{Authors' contributions}

MCol expressed and purified both unlabeled and ${ }^{15} \mathrm{~N}$ labeled IRF-3 RD and searched for buffer conditions leading to a monomeric form. He also purified XD and both unlabeled and ${ }^{15} \mathrm{~N}$-labeled $\mathrm{N}_{\text {TAIL' }}$ performed co-immunoprecipitation and co-precipitation experiments from bacterial lysates, carried out CD and fluorescence studies and prepared samples for NMR and EPR studies. JMB cloned IRF-3 RD and carried out preliminary interaction studies with a dimeric form of IRF-3 RD. CC carried out yeast twohybrid experiments. CS cloned IRF-3 cDNA by RT-PCR. SV carried out co-immunoprecipitation experiments in human cells. SC purified and spin-labeled $\mathrm{N}_{\text {TAIL }}$ cys variants. $\mathrm{VB}$ and $\mathrm{AF}$ recorded the EPR spectra, while HD recorded the NMR spectra. MCou participated to coimmunoprecipitation and co-precipitation experiments from bacterial lysates. SL and DG are both responsible for the study design and coordination of the work, with SL being in charge of molecular biology, biochemistry and biophysics aspects and DG being in charge of cellular biology aspects. The manuscript was written by SL with an important contribution by DG. All authors read and approved the final manuscript.

\section{Acknowledgements}

This work is dedicated to the memory of Bruno Curti. He was an excellent teacher and a brilliant scientist. He largely contributed to SL's decision to become a scientist.

This work was supported by the CNRS, and by the Agence Nationale de la Recherche, specific program "Microbiologie et Immunologie", ANR-05MIIM-035-02, "Structure and disorder of measles virus nucleoprotein: molecular partnership and functional impact".

The authors wish to thank Cédric Bernard for help in recording the HSQC spectra, Laurent Vuillard and Anatoly Dragan for useful advice on the purification of IRF-3 RD, Giuliano Sciara for precious advice and help on the SEC combined to the multi-angle laser light-scattering technology, Bruno Guigliarelli for support in EPR experiments, Christophe Flaudrops for MALDI-TOF analysis, Renaud Vincentelli for help with automated hold-up and pull-down experiments, and $\mathrm{P}$ Colas and Aptanomics for useful $\mathrm{Y} 2 \mathrm{H}$ reagents and kind advice. We are also grateful to Michael Oglesbee for stimulating discussions and critical reading of the manuscript.

\section{References}

I. Lamb RA, Kolakofsky D: Paramyxoviridae: The Viruses and Their Replication. In "Fields Virology" 4th edition. Edited by: Fields BN, Knipe DM, Howley PM. Lippincott-Raven, Philadelphia, PA; 2001:1305-1340.

2. Karlin D, Longhi S, Canard B: Substitution of two residues in the measles virus nucleoprotein results in an impaired self-association. Virology 2002, 302:420-432.

3. Kingston RL, Walter AB, Gay LS: Characterization of nucleocapsid binding by the measles and the mumps virus phosphoprotein. J Virol 2004, 78:8615-8629.

4. Longhi S, Receveur-Brechot V, Karlin D, Johansson K, Darbon $H$, Bhella D, Yeo R, Finet S, Canard B: The C-terminal domain of the measles virus nucleoprotein is intrinsically disordered and folds upon binding to the C-terminal moiety of the phosphoprotein. J Biol Chem 2003, 278: I8638-18648.

5. Heggeness MH, Scheid A, Choppin PW: Conformation of the helical nucleocapsids of paramyxoviruses and vesicular stomatitis virus: reversible coiling and uncoiling induced by changes in salt concentration. Proc Natl Acad Sci USA 1980, 77:2631-2635.

6. Heggeness $M H$, Scheid A, Choppin PW: The relationship of conformational changes in the Sendai virus nucleocapsid to proteolytic cleavage of the NP polypeptide. Virology 1981, I | 4:555-562.

7. Wright PE, Dyson HJ: Intrinsically unstructured proteins: reassessing the protein structure-function paradigm. I Mol Biol 1999, 293:321-331.

8. Uversky VN, Gillespie JR, Fink AL: Why are "natively unfolded" proteins unstructured under physiologic conditions? Proteins 2000, 4 I:4I 5-427.

9. Dunker AK, Lawson JD, Brown C], Williams RM, Romero P, Oh JS, Oldfield CJ, Campen AM, Ratliff CM, Hipps KW, Ausio J, Nissen MS, Reeves R, Kang C, Kissinger CR, Bailey RW, Griswold MD, Chiu W, Garner EC, Obradovic ZI: Intrinsically disordered protein. J Mol Graph Model 2001, 19:26-59.

10. Dunker AK, Obradovic Z: The protein trinity - linking function and disorder. Nat Biotechnol 200I, 19:805-806. 
11. Tompa P: Intrinsically unstructured proteins. Trends Biochem Sci 2002, 27:527-533.

12. Uversky VN: Natively unfolded proteins: a point where biology waits for physics. Protein Sci 2002, I I:739-756.

13. Tompa P: The functional benefits of disorder. J Mol Structure (Theochem) 2003, 666-67:36I-37I.

14. Fink AL: Natively unfolded proteins. Curr Opin Struct Biol 2005 , I5:35-4I.

15. Dyson HJ, Wright PE: Intrinsically unstructured proteins and their functions. Nat Rev Mol Cell Biol 2005, 6: 197-208.

16. Uversky VN, Oldfield CJ, Dunker AK: Showing your ID: intrinsic disorder as an ID for recognition, regulation and cell signaling. J Mol Recognit 2005, 18:343-384.

17. Radivojac P, lakoucheva LM, Oldfield CJ, Obradovic Z, Uversky VN, Dunker AK: Intrinsic disorder and functional proteomics. Biophys J 2007, 92: | 439-1456.

18. Dunker AK, Oldfield CJ, Meng J, Romero P, Yang JY, Chen JW, Vacic V, Obradovic Z, Uversky VN: The unfoldomics decade: an update on intrinsically disordered proteins. BMC Genomics 2008, 9(Suppl 2):SI.

19. Dunker AK, Silman I, Uversky VN, Sussman JL: Function and structure of inherently disordered proteins. Curr Opin Struct Biol 2008, I8:756-764

20. Zhang X, Glendening C, Linke H, Parks CL, Brooks C, Udem SA, Oglesbee $M$ : Identification and characterization of a regulatory domain on the carboxyl terminus of the measles virus nucleocapsid protein. J Virol 2002, 76:8737-8746.

21. Zhang X, Bourhis JM, Longhi S, Carsillo T, Buccellato M, Morin B, Canard $B$, Oglesbee $M$ : $\mathbf{H s p 7 2}$ recognizes a $\mathbf{P}$ binding motif in the measles virus $\mathbf{N}$ protein C-terminus. Virology 2005, 337:162-174.

22. Laine $D$, Trescol-Biémont $M$, Longhi $S$, Libeau G, Marie J, Vidalain $P$, Azocar O, Diallo A, Canard B, Rabourdin-Combe C, Valentin H Measles virus nucleoprotein binds to a novel cell surface receptor distinct from FcgRII via its C-terminal domain: role in MV-induced immunosuppression. J Virol 2003, 77: II332-11346.

23. Laine D, Bourhis J, Longhi S, Flacher M, Cassard L, Canard B, SautèsFridman C, Rabourdin-Combe C, Valentin H: Measles virus nucleoprotein induces cell proliferation arrest and apoptosis through NTAIL/NR and NCORE/FcgRIIBI interactions, respectively. I Gen Virol 2005, 86: I77/-I784.

24. tenOever BR, Servant MJ, Grandvaux N, Lin R, Hiscott J: Recognition of the Measles Virus Nucleocapsid as a Mechanism of IRF-3 Activation. J Virol 2002, 76:3659-3669.

25. Hiscott J: Triggering the innate antiviral response through IRF-3 activation. J Biol Chem 2007, 282:15325-I5329.

26. Johansson K, Bourhis JM, Campanacci V, Cambillau C, Canard B, Longhi S: Crystal structure of the measles virus phosphoprotein domain responsible for the induced folding of the C-terminal domain of the nucleoprotein. I Biol Chem 2003, 278:44567-44573.

27. Oldfield CJ, Cheng Y, Cortese MS, Romero P, Uversky VN, Dunker AK: Coupled Folding and Binding with alpha-Helix-Forming Molecular Recognition Elements. Biochemistry 2005, 44:12454-12470.

28. Bourhis J, Johansson K, Receveur-Bréchot V, Oldfield CJ, Dunker AK, Canard B, Longhi S: The C-terminal domain of measles virus nucleoprotein belongs to the classof intrinsically disordered proteins that fold upon binding to their pohysiological partner. Virus Research 2004, 99:157-167.

29. Morin B, Bourhis JM, Belle V, Woudstra M, Carrière F, BGuigliarelli B, Fournel $A$, Longhi $S$ : Assessing induced folding of an intrinsically disordered protein by site-directed spin-labeling EPR spectroscopy. J Phys Chem B 2006, I I 0:20596-20608.

30. Belle V, Rouger S, Costanzo S, Liquiere E, Strancar J, Guigliarelli B, Fournel A, Longhi S: Mapping alpha-helical induced folding within the intrinsically disordered C-terminal domain of the measles virus nucleoprotein by site-directed spin-labeling EPR spectroscopy. Proteins 2008, 73:973-988.

31. Kingston RL, Hamel DJ, Gay LS, Dahlquist FW, Matthews BW: Structural basis for the attachment of a paramyxoviral polymerase to its template. Proc Natl Acad Sci USA 2004, 101:830 I-8306.

32. Qin BY, Liu C, Lam SS, Srinath H, Delston R, Correia J], Derynck R, Lin K: Crystal structure of IRF-3 reveals mechanism of autoinhibition and virus-induced phosphoactivation. Nat Struct Biol 2003, 10:913-921.

33. Qin BY, Liu C, Srinath H, Lam SS, Correia JJ, Derynck R, Lin K: Crystal structure of IRF-3 in complex with CBP. Structure 2005 13:1269-1277.

34. Demarest SJ, Deechongkit S, Dyson HJ, Evans RM, Wright PE: Packing, specificity, and mutability at the binding interface between the pl60 coactivator and CREB-binding protein. Protein Sci 2004, 13:203-210.

35. Chen M, Cortay JC, Logan IR, Sapountzi V, Robson CN, Gerlier D: Inhibition of ubiquitination and stabilization of human ubiquitin E3 ligase PIRH2 by measles virus phosphoprotein. J Virol 2005, 79: I 1824-11836.

36. Plumet S, Gerlier D: Optimized SYBR green real-time PCR assay to quantify the absolute copy number of measles virus RNAs using gene specific primers. J Virol Methods 2005, I 28:79-87.

37. Brizzard BL, Chubet RG, Vizard DL: Immunoaffinity purification of FLAG epitope-tagged bacterial alkaline phosphatase using a novel monoclonal antibody and peptide elution. Biotechniques 1994, 16:730-735.

38. Bourhis JM, Receveur-Bréchot V, Oglesbee M, Zhang X, Buccellato M, Darbon $\mathrm{H}$, Canard $\mathrm{B}$, Finet $\mathrm{S}$, Longhi $\mathrm{S}$ : The intrinsically disordered C-terminal domain of the measles virus nucleoprotein interacts with the C-terminal domain of the phosphoprotein via two distinct sites and remains predominantly unfolded. Protein Sci 2005, I 4: 1975-1992.

39. Uversky VN: Use of fast protein size-exclusion liquid chromatography to study the unfolding of proteins which denature through the molten globule. Biochemistry 1993, 32:13288-13298.

40. Mori S, Abeygunawardana C, Johnson MO, van Zijl PC: Improved sensitivity of HSQC spectra of exchanging protons at short interscan delays using a new fast HSQC (FHSQC) detection scheme that avoids water saturation. J Magn Reson B 1995, 108:94-98.

41. Piotto M, Saudek V, Sklenar V: Gradient-tailored excitation for single-quantum NMR spectroscopy of aqueous solutions. Biomol NMR 1992, 2:66I-665.

42. Chen M, Cortay JC, Gerlier D: Measles virus protein interactions in yeast: new findings and caveats. Virus Res 2003, 98:123-129.

43. Feix JB, Klug CS: Site-directed spin-labeling of membrane proteins and peptide-membrane interactions. In Biological magnetic resonance. Volume Spin labeling: the next millenium New York: Plenum Press; 1998:25I-28I.

44. Hubbell WL, Gross A, Langen R, Lietzow MA: Recent advances in site-directed spin labeling of proteins. Curr Opin Struct Biol 1998 8:649-656.

45. Biswas R, Kuhne H, Brudvig GW, Gopalan V: Use of EPR spectroscopy to study macromolecular structure and function. $\mathrm{SC}$ Prog 200I, 84:45-67.

46. Shi $Y, W u$ J: Structural basis of protein-protein interaction studied by NMR. I Struct Funct Genomics 2007, 8:67-72.

47. Kriwacki RW, Hengst L, Tennant L, Reed SI, Wright PE: Structural studies of p2IWafl/Cipl/Sdil in the free and Cdk2-bound state: conformational disorder mediates binding diversity. Proc Natl Acad Sci USA 1996, 93: I I504-I I 509.

48. Luby-Phelps K: Cytoarchitecture and physical properties of cytoplasm: volume, viscosity, diffusion, intracellular surface area. Int Rev Cytol 2000, 192:189-22I.

49. Diallo A, Barrett T, Barbron M, Meyer G, Lefevre PC: Cloning of the nucleocapsid protein gene of peste-des-petits-ruminants virus: relationship to other morbilliviruses. J Gen Virol 1994, 75(Pt I):233-237.

50. Delannoy S, Urbatsch IL, Tombline G, Senior AE, Vogel PD: Nucleotide binding to the multidrug resistance $P$-glycoprotein as studied by ESR spectroscopy. Biochemistry 2005, 44:14010-14019.

51. Murakami K, Andree PJ, Berliner LJ: Metal ion binding to alphalactalbumin species. Biochemistry 1982, 21:5488-5494.

52. Charbonnier S, Zanier K, Masson M, Trave G: Capturing proteinprotein complexes at equilibrium: the holdup comparative chromatographic retention assay. Protein Expr Purif 2006, 50:89-101.

53. Vincent S, Tigaud I, Schneider H, Buchholz CJ, Yanagi Y, Gerlier D: Restriction of measles virus RNA synthesis by a mouse host 
cell line: trans-complementation by polymerase components or a human cellular factor(s). J Virol 2002, 76:6121-6130.

54. Bourhis JM, Canard B, Longhi S: Structural disorder within the replicative complex of measles virus: functional implications. Virology 2006, 344:94-110.

55. Chen W, Srinath H, Lam SS, Schiffer CA, Royer WE Jr, Lin K: Contribution of Ser386 and Ser396 to activation of interferon regulatory factor 3. J Mol Biol 2008, 379:25I-260.

Publish with Biomed Central and every scientist can read your work free of charge

"BioMed Central will be the most significant development for disseminating the results of biomedical research in our lifetime. " Sir Paul Nurse, Cancer Research UK

Your research papers will be:

- available free of charge to the entire biomedical community

- peer reviewed and published immediately upon acceptance

- cited in PubMed and archived on PubMed Central

- yours - you keep the copyright

Submit your manuscript here:

http://www.biomedcentral.com/info/publishing_adv.asp
BioMedcentral 